\title{
Can MCDA guide transdisciplinary endeavors? A framework applied to co-developing a flood forecasting system in West Africa
}

\author{
Judit Lienert ${ }^{1}$, Jafet Andersson ${ }^{2}$, Daniel Hofmann ${ }^{1}$, Francisco Silva Pinto ${ }^{1}$, Martijn Kuller ${ }^{1}$ \\ ${ }^{1}$ Eawag: Swiss Federal Institute of Aquatic Science \& Technology, Environmental Social Sciences (ESS) Department, Ueber- \\ 5 landstrasse 133, 8600 Duebendorf, Switzerland \\ ${ }^{2}$ Swedish Meteorological and Hydrological Institute (SMHI), Hydrology Research, 60176 Norrköping, Sweden
}

Correspondence to: Judit Lienert (judit.lienert@eawag.ch)

\begin{abstract}
Climate change is projected to increase flood risks in West Africa. The EU Horizon 2020 project FANFAR codesigned a pre-operational flood forecasting and alert system for West Africa in four workshops with 50-60 stakeholders from 17 countries, adopting a Multi-Criteria Decision Analysis (MCDA) process. Firstly, we aimed to find a robust configuration of the FANFAR system. We document empirical evidence of MCDA, including stakeholder analysis, jointly creating 10 objectives, and 11 FANFAR system configurations. Stakeholders found it most important that the system produces accurate, clear, and accessible flood risk information, well before floods. Monte Carlo simulation and sensitivity analyses helped identifying three configurations that were robust despite uncertainty of expert predictions and different stakeholder preferences,

15 elicited in group sessions. Secondly, we investigated if problem structuring helps focus early technical system development. Although partly achieved, full MCDA was necessary to provide convincingly robust configurations. Thirdly, we critically analyzed MCDA based on literature from sustainability science and transdisciplinary research. Our proposed framework consists of three steps: co-design (joint problem framing), co-production (doing research), and co-dissemination and evaluation of integrated knowledge. MCDA met many requirements, but not all. In step 1, participatory MCDA with problem structuring provides a consistent methodology, and can identify stakeholders and shared objectives to foster joint understanding. MCDA successfully contributes to step 2 by combining interdisciplinary expert knowledge, integrating conflicting stakeholder preferences, handling uncertainty, and providing unambiguous, shared results. Many elements of step 3 are not met by MCDA. We discuss this framework and using MCDA for transdisciplinary hydrology research that engages with stakeholders and society.
\end{abstract}

\section{Introduction}

\subsection{Floods in West Africa}

West Africa is vulnerable to the projected impacts of climate change, particularly related to runoff quantities (Aich et al., 2016; Roudier et al., 2014). While the mechanisms and projections remain uncertain for West Africa, there is growing evidence for increased frequency, magnitude, and impact of fluvial floods (Nka et al., 2015). West Africa is already heavily impacted by floods. Preliminary data from the United Nations estimate that 465 people died from floods in West and Central Africa in 
30 2020. More than 1.7 million people were affected (double the number of 2019), 94'000 people were displaced, and 152’000 houses were destroyed (OCHA, 2020). Worldwide, good operational flood forecast systems, giving accurate, timely, precise, and understandable forecast information and alerts, provide effective and affordable help to anticipate and minimize flood impacts (Perera et al., 2019). Several systems have been set up for different West African regions, some being very useful. However, none seem to sufficiently meet stakeholder needs regarding: i) timeliness (e.g., annual frequency of the PRESASS and PRESAGG seasonal forecasts; WMO, 2021); ii) coverage (e.g., systems propagating streamflow measurements such as SLAPIDS, OPIDIN, FEWS-Oti often only cover a small part of West Africa and do not predict in ungauged basins; Massazza et al., 2020); iii) up-to-date operational production because many models are used only for research (e.g., Aich et al., 2016; Schuol et al., 2008), and sometimes systems fail due to e.g., interrupted data flows or server failures (e.g., SATH-NBA in the major 2020 floods; NBA, 2020); iv) accuracy (e.g., global modelling systems such as GloFAS; Passerotti et al., 2020); and v) openness and ownership (e.g., proprietary closed source consultancy systems, which may limit the capacity and independence of West African scientists and practitioners, and hence the systems' long-term sustainability).

\subsection{The FANFAR project}

The EU Horizon 2020 project FANFAR, running from 2018 to 2021 addresses these gaps (FANFAR, 2021). FANFAR operates in a transnational and transcontinental context, with consortium partners across Europe (Italy, Spain, Sweden, and Switzerland) and Africa (organizations AGRHYMET and NIHSA). It includes stakeholders across 17 countries of West and Central Africa. FANFAR establishes and reinforces existing cooperation between European and West African hydrologists, information and communication technology (ICT) experts, decision analysts, and end users such as West African hydrologists and emergency managers (Andersson et al., 2020a) to co-develop a pre-operational flood forecasting and alert system at West Africa scale ("FANFAR system"). It is currently based on three open-source hydrological models, Niger-HYPE, West Africa HYPE, and World-Wide HYPE (Andersson et al., 2017; Arheimer et al., 2020), employed in a cloud-based ICT environment. The daily forecasting chain includes meteorological reanalysis and forecasting, data assimilation of gauge observations and satellite altimetry, hydrological initialization and forecasting, flood alert derivation, and distribution through Email, SMS, API, and a web based Interactive Visualization Portal (IVP, https://fanfar.eu/ivp/). In this paper, we do not address the technical system and refer interested readers to Andersson et al. (2020b). Rather, we emphasize the complex development of the FAN-

55 FAR system in an iterative co-design process, the necessity of which has been recently underlined by Sultan et al. (2020). At its core are three one-week workshops carried out in West Africa from 2018-2020, each with 50-60 participants, and online workshops in 2021. We organized stakeholder participation adopting a comprehensive Multi-Criteria Decision Analysis (MCDA) process (Belton and Stewart, 2002;Eisenführ et al., 2010;Keeney, 1982) that includes problem structuring methods (PSMs; Rosenhead and Mingers, 2001). Using MCDA, we integrated the stakeholders' preferences in the expert assessment 60 of how well different FANFAR system configurations meet stakeholder objectives. Ideally, this helps focus system development on configurations that best meet expectations, given the possibility of contradictory interests concerning the importance of objectives, and uncertainty about how well a system configuration can achieve the objectives. 
MCDA has been used in flood risk management (reviewed by de Brito and Evers, 2016;Abdullah et al., 2021), but rarely focusing on a participatory stakeholder process. Stakeholders were not even mentioned in a review of 149 papers (Abdullah et al., 2021). The other review concluded that stakeholder participation was fragmented, despite being reported in $51 \%$ of 128 papers, i.e., stakeholders only assigned importance weights to objectives, but were not involved in the entire decision process (de Brito and Evers, 2016). Participatory processes involving researchers and non-scientific actors are extensively discussed in literature from sustainability sciences (e.g., Caniglia et al., 2021;Norstrom et al., 2020) and transdisciplinary research (e.g., Jahn et al., 2012;Lang et al., 2012;Mauser et al., 2013; Schneider et al., 2019; Wuelser et al., 2021). With this paper we combine two fields. We draw from this literature emphasizing continuous stakeholder participation to achieve societal transformation. We use MCDA as integrative methodological process, which in flood risk management seems to have been mainly used as a technical method, without broader stakeholder participation (de Brito and Evers, 2016). To the best of our knowledge, we are not aware of systematic assessment of MCDA processes from the angle of transdisciplinary sustainability research.

\subsection{Aims, research questions, and structure of paper}

75 The aim of the FANFAR project is to co-design and co-develop a pre-operational flood forecasting and alert system at West Africa scale. For the stakeholders in West Africa, and ultimately for thousands of people affected by floods, it is of prime importance to find a good configuration of a flood forecast and alert system. "Good" means that it satisfies the main needs of those that are meant to use it: the hydrological services and emergency management agencies (Research Question A; RQA). Moreover, there was a timing issue. The IT specialists and hydrologists could not wait with technical system development until all stakeholder information had been gathered and analyzed with MCDA. We thus needed to rely on preliminary information early in the project, which was refined as the project progressed (RQB). This leads to following research questions:

- RQA: What characterizes a good regional flood forecasting and alert system for West Africa? Is it possible to identify a robust FANFAR system configuration, despite uncertainty (of expert predictions about FANFAR system performance and MCDA model) and possibly different preferences of stakeholders regarding what the system should achieve?

- RQB: How can problem structuring at the beginning of the project help focus the development of the FANFAR system to meet the stakeholders' expectations (i.e., before MCDA results are available)?

According to the call of this Special Issue: “(...) we need to remind ourselves that a scientific decade on change in hydrology and society requires the perspectives of those disciplines that have traditionally been concerned with society (...). While interdisciplinary conversations have been happening to some extent, transdisciplinary endeavors remain largely undocumented"

90 (Carr et al., 2021). We aimed to document empirical evidence from the FANFAR project, contributing to knowledge production, learning, and scientific praxis in hydrology. Taking a more theoretical stance, we aimed to critically analyze FANFAR from the perspective of knowledge co-creation, sustainability science, and transdisciplinary research. We focused on MCDA as a process, rather than a technical method (sect. 2.2; Figure 1). We set up a framework drawing from literature to uncover strengths and weaknesses of MCDA to guide the transdisciplinary process (RQC). We summarized insights and recommendations of special interest to hydrology praxis when engaging with stakeholders (RQD). The specific research questions are: 
- RQC: How suitable is a structured, participatory decision analysis process based on MCDA for guiding large transdisciplinary projects? What worked well or less well in FANFAR? Could interests of a large number of stakeholders be integrated?

- RQD: Is the proposed framework useful for this type of evaluation? What insights and recommendations can we provide for future transdisciplinary projects in hydrology research?

100 The paper is organized as follows: In the Methods, we review main elements of frameworks in the sustainability science and transdisciplinary research literature (sect. 2.1), followed by a framework proposition (sect. 2.1.1). We shortly review literature on MCDA in flood risk management (2.2.1) and motivate using MCDA to structure stakeholder participation (sect. 2.2.2). We present the workshops in West Africa (sect. 2.2.3), and the methods in each MCDA step (sects. 2.2.4 - 2.2.11). In the Results (sect. 3), we present problem structuring steps of MCDA including stakeholder analysis, the final MCDA results, and sensitivity analyses to test robustness of best performing FANFAR system configurations under changing model assumptions. The Discussion follows the research questions: finding a robust FANFAR system configuration with MCDA (RQA, sect. 4.1) and whether early problem structuring helped system design (RQB, sect. 4.2). We analyze MCDA following the proposed framework of transdisciplinary research (RQC, sect. 4.3). We conclude by summarizing insights regarding the framework and recommendations for using an MCDA process in hydrology research, engaging with stakeholders and society (RQD; sect. 5).

\section{Methods}

\subsection{Sustainability science and transdisciplinary research frameworks}

Disaster management increasingly acknowledges that developing early warning systems should closely involve users to increase the systems' usefulness (adapted to user needs) and effectiveness (e.g., enhance uptake; Basher, 2006;Bierens et al., 2020;UNISDR, 2010). This follows a trend calling for "collaborative action", "collaborative governance", and "co-production

115 of knowledge" in many fields, e.g., healthcare (Donetto et al., 2015). Sustainability science stresses that societal transformation is needed to address today's global environmental challenges. This requires close engagement of academia with societal actors to co-produce and integrate knowledge (e.g., Caniglia et al., 2021;Lang et al., 2012;Mauser et al., 2013;Norstrom et al., 2020; Schneider et al., 2019; Wuelser et al., 2021). Transdisciplinary research emphasizes collaboration between different scientific disciplines, and between researchers and practitioners (Jahn et al., 2012). It seeks to support societal problem solving with "situated knowledge" for a specific problem in its socio-ecological context (Wuelser et al., 2021). Many collaborative, transdisciplinary projects involving non-scientific stakeholders are being carried out. However, there is still a lack of systematic integration and conceptualization of empiric evidence (e.g., Lang et al., 2012;Caniglia et al., 2021), and of understanding the extent and mechanisms of advancing sustainability transformations (Schneider et al., 2019; Wuelser et al., 2021).

Frameworks for collaborative governance usually consist of stages such as inputs, research processes, direct outputs, and

125 further outcomes (Schneider et al., 2019). Earlier conceptual frameworks stem from transdisciplinary literature. Main phases in such iterative processes are: (i) forming a common research object (see Figure 1 in Jahn et al., 2012), problem framing and 
team building (see Figure 1 in Lang et al., 2012); (ii) co-creating solution oriented and transferable knowledge through collaborative research; (iii) applying the co-produced knowledge (Lang et al., 2012), and evaluating its contribution to societal and scientific progress (Jahn et al., 2012). Similar three steps were proposed by an international initiative, where the co-creation of knowledge for addressing global sustainability problems was divided into: (i) co-design; (ii) co-production; and (iii) codissemination of knowledge, involving academia and stakeholders throughout (see Figure 3 in Mauser et al., 2013). Co-design includes joint framing of the sustainability challenges faced by society, research definition, and implementation (e.g., funding). Co-production includes methodologically consistent scientific integration of interdisciplinary knowledge, including ways for dealing with the uncertainty of results. The co-produced knowledge should be societally relevant, which is ensured by continuous interaction with stakeholders. Co-dissemination of results includes scientific publications and products that are accessible and understandable by different societal groups. There should be transparent discussion of results, especially among groups of conflicting interests, and consequential action should be taken.

Two recent articles in "Nature Sustainability" propose frameworks sharing similar elements, but with different structuring. Caniglia et al. (2021) suggest that research actions for sustainability create transformative change in three dimensions: (i)

140 knowledge informing intentional design; (ii) knowledge enhancing shared agency by involving multiple actors; and (iii) knowledge enabling contextual realization in constantly changing environments. These are further characterized by prescriptive knowledge (recommendations about more desirable options), co-produced knowledge (through collaborative engagement with actors, incorporating their diverse perspectives and interests), and situated knowledge (tailored to specific contexts; see Table 2 in Caniglia et al., 2021). In a more practical perspective, four guiding principles for evaluating the quality and success

145 of co-production processes were proposed by 36 sustainability researchers, underpinned with examples (see Figure 1 in Norstrom et al., 2020). These are: (i) context-based (situate process in particular context, place, or issue); (ii) pluralistic (recognize multiple ways of knowing and doing); (iii) goal-oriented (articulate clearly defined, shared goals); and (iv) interactive (ongoing learning among actors, active engagement, and frequent interactions).

Recent studies systematically evaluated transdisciplinary projects to identify common characteristics that are re-usable in other cases (Wuelser et al., 2021). Analyzing 12 Swiss transdisciplinary research projects, seven types of transferable knowledge were proposed (see Table 2 in Wuelser et al., 2021): (i) transdisciplinary principles (e.g., take practitioners on board from the start); (ii) transdisciplinary approaches (procedural, e.g., joint problem identification, strategies for building alliances with regional partners); (iii) systematic procedures (e.g., specific methodologies); (iv) product formats (communicate and use research results in practice, e.g., capacity building); (v) experiential know-how (personal learnings, skills, and experiences); (vi)

155 framings (definitions, descriptions of issues); and (vii) insights, data, and information (results, outputs). Similarly, 31 international transdisciplinary projects were systematically analyzed for identifying generic mechanisms of creating societal impacts (see Figure 1 and Table 2 in Schneider et al., 2019). Three distinct mechanisms and seven strategies were identified: (i) promote 
systems, target, and transformation knowledge (by providing 1. access to information; 2. advice and training; 3 . public debates); (ii) foster social learning for collective action (4. multi-stakeholder groups; 5. North-South partnerships); and (iii) enhance competences for reflective leadership (6. transformative education; 7. communities of practice).

The last example stems from earth systems sciences, using a case study for climate assessment as starting point for conceptual insights, rather than firstly drawing from social science theories as most above examples (Lemos and Morehouse, 2005). These authors argue for interactive models (= frameworks) and iterative processes to increase innovation and societal impact across three dimensions: (i) interdisciplinarity (effort of scientists from different disciplines to tackle complex problems, working together iteratively, but separately if necessary); (ii) interaction with stakeholders (e.g., problem definition, testing and disseminating results, adapting research to users' needs, building trust); and (iii) production of usable knowledge.

\subsubsection{Evaluation framework for transdisciplinary MCDA process}

We use common elements from these frameworks to analyze the transdisciplinary co-design process based on MCDA. We emphasize elements that are crucial for the practice-oriented FANFAR project, aiming to produce a user friendly, but technically complex flood forecast and alert system. Some elements are especially relevant to earth systems sciences, e.g., climate assessment (Lemos and Morehouse, 2005), but received less attention in the social science oriented sustainability and transdisciplinary research literature: explicit consideration of uncertainty, and the interdisciplinary effort needed for tackling technically complex problems (Lemos and Morehouse, 2005;Mauser et al., 2013). We follow a stepwise timeline, as proposed by many (Jahn et al., 2012;Lang et al., 2012;Mauser et al., 2013), using the terminology by Mauser et al. (2013): (i) co-design; (ii) co-production, and (iii) co-dissemination of knowledge (to which we add evaluation), involving academia and stakeholders throughout. For each phase, we include specific elements appropriate for our context (Table 1).

Table 1. Conceptual framework for transdisciplinary research based on literature: (1) co-design, (2) co-production, and (3) codissemination of knowledge (terminology from Mauser et al., 2013), used to assess the MCDA process in the FANFAR project.

\begin{tabular}{llll}
\hline \hline ID & Step & Explanation & Literature examples \\
\hline $\mathbf{1}$ & Co-design & Joint problem framing & \\
1a & $\begin{array}{l}\text { Build collaborative } \\
\text { research team }\end{array}$ & Include structures enabling participation from the start, e.g., & (Lang et al., 2012;Wuelser et al., \\
& & use stakeholder mapping; aim at legitimacy of team; include & 2021;Norstrom et al., 2020) \\
& & bridging organizations or knowledge brokers to increase trust & \\
1b & $\begin{array}{l}\text { Define research } \\
\text { questions, methodo- tice; define meaningful, shared goals, and measures of success }\end{array}$ & 2013;Jahn et al., 2012;Wuelser et \\
& logical framework & & al., 2021;Lemos and Morehouse,
\end{tabular}

1c Define boundary Translate problem into boundary object that allows re-integrat- (Lang et al., 2012;Jahn et al., object ing insights into societal implementation and scientific body of 2012;Schneider et al., 2019) 
knowledge; "transformation knowledge" on how to make

change e.g., with measures and tools

\section{Co-production Conducting integrated research to produce new knowledge; continuous exchange among} scientists from different disciplines, and with stakeholders

2a Apply integrative Facilitate differentiation of different bodies of knowledge by

(Mauser et al., 2013; Wuelser et (scientific) methods using appropriate systematic procedures that ensure methodo-

al., 2021;Lang et al., 2012;Jahn et logical consistency of research process al., 2012)

2b Interdisciplinary Integrate knowledge of scientists from different disciplines;

(Mauser et al., 2013;Lemos and collaboration avoid conflicting methodological standards

Morehouse, 2005;Jahn et al., 2012; Norstrom et al., 2020)

2c Explicitly consider Especially relevant in natural science problems addressing (Mauser et al., 2013) uncertainty long time horizons (e.g., climate change)

2d Integrate practice Ensure appropriate roles, range of perspectives and skills, and stakeholders in iter- context-based research; avoid discontinuous participation and ative process $\quad$ vagueness of results that conceal potential conflicts 2005; Norstrom et al., 2020)

2e Pluralistic principle/ Create shared understanding across multiple axes (e.g., disci(Norstrom et al., 2020;Schneider social learning plines, sectors, countries, gender); recognize values of people; foster training and capacity building 2021; Wuelser et al., 2021)

3 Co-dissemination Integrate and disseminate knowledge among research and societal groups in appropriate, and evaluation relevant way; transparent discussion, critical reflection, and consequential actions

3a Two-dimensional Review, discuss, and revise outcomes from societal and scien- (Lang et al., 2012;Caniglia et al., integration tific perspective, e.g., prescriptive knowledge (recommenda- 2021;Mauser et al., 2013) tions about more desirable options)

3b Generate targeted Translate results for scientific progress (e.g., generalizability), products and real-world problem solving (e.g., relevance, scaling up results, alliances, actions in specific contexts, products such as 2021;Caniglia et al., 2021;Lemos maps, manuals, information for policy makers); knowledge and Morehouse, 2005;Mauser et transfer by scientists and societal actors al., 2013)

3c Evaluate societal Reference back to success factors (step 1b); impact can be deand scientific imfined in many ways, e.g., research quality, media attention, (Lang et al., 2012;Jahn et al., pact download rates, communities of practice, social networks, capacity building, education, concrete products, changing people's lives; longer-term impacts are often not measurable 2012; Norstrom et al., 2020; Schneider et al., 2019; Lemos and Morehouse, 2005) 


\subsection{Multi-Criteria Decision Analysis (MCDA)}

180

\subsubsection{MCDA in flood risk research}

Methodological and epistemological perspectives in transdisciplinary research may still be debated (Jahn et al., 2012), but there needs to be consensus on methods used in a project, and the concept to integrate research (Lang et al., 2012). The FANFAR consortium agreed on Multi-Criteria Decision Analysis (MCDA) as organizing framework to integrate West African stakeholders in the transdisciplinary process and achieve the aim of producing the FANFAR system. MCDA is increasingly popular in hydrology, and specifically related to flood risks. A brief literature search revealed around 50 potentially relevant articles, but only few actually included stakeholders (Web of Science search 25.08.2021; keywords: "MCDA" AND "hydrolog*" AND/OR “flood*”). This corroborates results of two recent reviews (de Brito and Evers, 2016;Abdullah et al., 2021). Both confirm a significant growth in MCDA applications, especially for flood mitigation, while flood preparedness, response, or recovery phases were understudied. Moreover, uncertainty analysis and stakeholder participation were rarely applied, and require future exploration to increase the quality of decision making and success of implementation (de Brito and Evers, 2016). Our search indicates that most papers used MCDA as a technical method to (mathematically) integrate over various indicators, e.g., to support calibration of flood forecasting models (Pang et al., 2019). Recent methodologically interesting papers addressed MCDA coupled with e.g., artificial intelligence (Pham et al., 2021), machine learning (Nachappa et al., 2020), or portfolio decision analysis (Convertino et al., 2019). Combining GIS with MCDA is a trend in hydrology, as in other fields. Examples include flood risk assessment explicitly including uncertainty (Tang et al., 2018), a method to produce risk maps for a Swiss region (Ronco et al., 2015), and flood risk analyses and mappings for specific cases (e.g., Samanta et al., 2016).

This literature seems to lack integrating stakeholders in the decision analysis process, even in applied cases, a main conclusion of the review by de Brito and Evers (2016). These authors also propose a concept for inter- and transdisciplinary approaches to improve urban resilience in flood risk management using MCDA (Evers et al., 2018), and present a participatory case study in Brazil for flood vulnerability assessment (de Brito et al., 2018). Several studies state that MCDA results are highly susceptible to model assumptions, especially the weights assigned to objectives (de Brito and Evers, 2016). For instance, the sensitivity of MCDA results to weight variability was determined with global sensitivity analysis (Tang et al., 2018). In some of our screened papers, stakeholders actively participated, but again mainly to assign weights. However, most papers we checked seem technical, and stakeholder involvement was usually described in few sentences, presenting the weights in a table, without

205 further elaboration of the process (e.g., Ronco et al., 2015). Concluding our short review, there seems to be a lack of research in hydrology that understands MCDA as a process, and that integrates stakeholders throughout this process.

\subsubsection{Overview of transdisciplinary MCDA process}

MCDA embraces various methodologies to support complex decisions (e.g., Belton and Stewart, 2002; de Brito and Evers, 2016). We chose MCDA, and specifically Multi-Attribute Value Theory (MAVT; Eisenführ et al., 2010;Keeney, 1982) for 
several reasons: (i) to develop a complex forecast system, many decisions had to be made. We needed to clarify, which hydrological models and data should be used to produce flood forecasts (e.g., type of meteorological forecast data, streamflow gauge observations), which flood hazard thresholds were appropriate, how to visualize model forecasts, or which distribution channels effectively reach people. MCDA is optimally suited to address such questions. (ii) Because the FANFAR system should be adapted to stakeholder needs, its development relied on close collaboration with nonacademic partners. MCDA is a proven methodology that allows close interaction with stakeholders at various stages of decision making processes, offering a choice of methods for each stage. (iii) We used MAVT because it bases decisions on the objectives that are of fundamental importance to stakeholders. (iv) To evaluate options (i.e., system configurations), MCDA allows comparing and integrating different kinds of scientific and technical data from expert predictions (e.g., accuracy of forecasts, estimated costs of system development) with stakeholders' preferences. Disentangling facts from values can be very helpful, especially if stakeholders have conflicting interests (Gregory et al., 2012a;Keeney, 1982). In most complex decisions, not all objectives can be fully achieved. MCDA explicitly asks stakeholders for the trade-offs they are willing to make. (v) MCDA allows including various types of uncertainty, e.g., of expert predictions with probability theory, or uncertain stakeholder preferences with sensitivity analyses (Reichert et al., 2015). (vi) MCDA is carried out stepwise, thus reducing complexity and increasing transparency. For these reasons, we used MCDA to identify a "Good flood forecast and alert system" for West Africa (see practical research questions RQA, RQB; sect. 1.1). We present the MCDA methods such that they are easily accessible and adaptable to other transdisciplinary projects, e.g., in hydrology, and provide extensive details as blueprint in the Supplementary Information. Based on our experiences, we critically analyzed the MCDA process using the transdisciplinary framework (Table 1) to understand which elements were met by MCDA (RQC, RQD; presented in sects. 4.3 and 5).

A typical MCDA process starts with joint problem framing (Figure 1), as in the co-design step 1 of the transdisciplinary framework (Table 1). Not part of MCDA sensu stricto were building the collaborative research team (step 1a), defining research questions and methodological framework (step 1b), and the boundary object, namely the FANFAR system (step 1c; Table 1). However, these steps were part of the FANFAR project with joint proposal writing and a kick-off meeting of European and West African consortium partners (section 2.2.3). As first step of the MCDA process, we undertook a stakeholder analysis (e.g., Grimble and Wellard, 1997;Lienert et al., 2013;Reed et al., 2009), which is often neglected in MCDA projects. This was especially important, as European researchers worked in an unfamiliar African context. Main identified stakeholders that participated in the workshops were representatives from hydrological services, emergency management agencies, river basin organizations, and regional expert agencies. Together with these priority stakeholders, we then identified objectives ("What is of fundamental importance to be achieved by a FANFAR system?") and options ("Which FANFAR system configurations are potentially suitable to achieve objectives?"). To support these first MCDA steps, diverse "Problem Structuring Methods" (PSMs) are available in other fields of decision analysis (Rosenhead and Mingers, 2001). It is common to combine MCDA with PSMs (reviewed by Marttunen et al., 2017). For a description of similar PSMs as used in FANFAR, we refer to an application in wastewater infrastructure planning (Lienert et al., 2015). The next steps 5-7 in MCDA (Figure 
1), belong to the transdisciplinary co-production step 2 (Table 1). Hereby, research is conducted to produce new knowledge, in continuous exchange between scientists from different disciplines and stakeholders. A transdisciplinary process is often iterative (e.g., Jahn et al., 2012;Lang et al., 2012), captured in the FANFAR project with several cycles of workshops with decision makers, end users, and stakeholders ("stakeholders" hereafter) to test, discuss, and improve the FANFAR pre-operational system. In the co-dissemination and evaluation step 3, this new knowledge is critically reflected, integrated, and disseminated (Table 1), captured in step 8 of a typical MCDA process (Figure 1). After summarizing the workshops in Africa (sect. 2.2.3), we focus on the steps of the MCDA process (sects. 2.2.4-2.2.10).

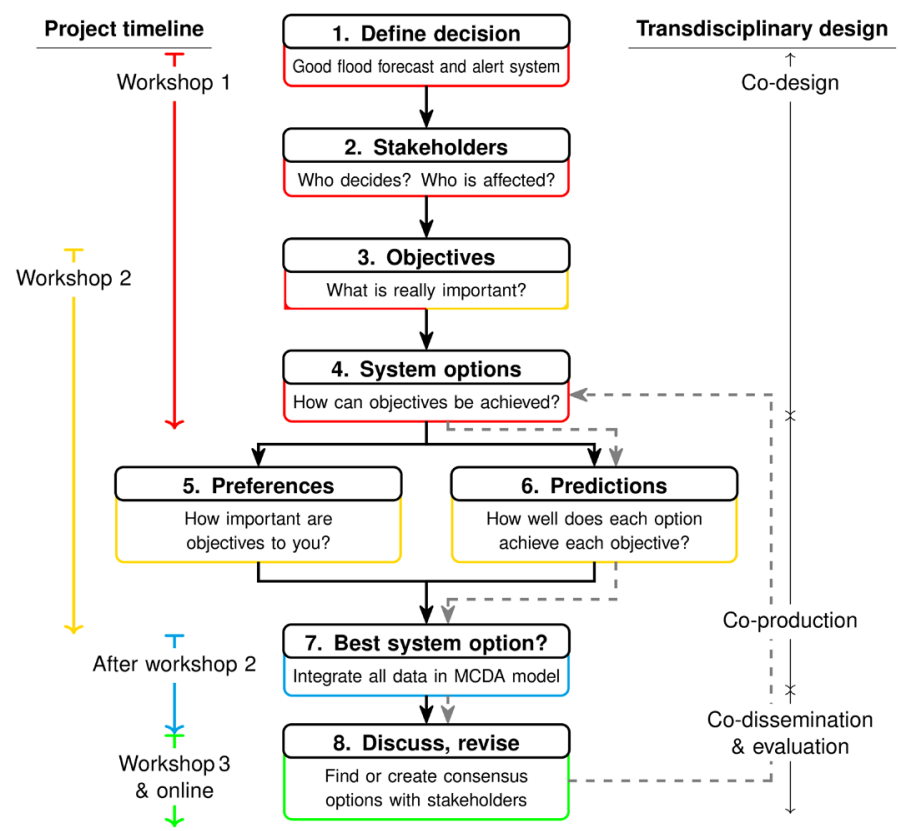

Figure 1: Multi-Criteria Decision Analysis (MCDA) is carried out stepwise in the FANFAR project. Explanations see text.

\subsubsection{Co-design workshops in West Africa}

We carried out three workshops in West Africa, and a kick off meeting of the FANFAR consortium in Norrköping (Sweden, 17-18 January 2018). A fourth workshop was replaced by two half-day online workshops due to COVID-19 (20-21 January 255 2021), and a final online workshop (01 June 2021). The workshops are documented in a detailed report (Lienert et al., 2020), and summary reports (FANFAR, 2021). At each workshop, West African representatives presented the flood situation in their country during rainy seasons and their experience with the FANFAR system. Each workshop hosted extensive technical sessions for experimentation with the latest FANFAR system, and structured technical feedback. Between workshops, the preoperational system was adapted to meet requests as well as possible (Andersson et al., 2020a). We also conducted sessions with emergency managers, e.g., about their understanding of flood risk representation to improve visualizations of the FANFAR system (Kuller et al., 2020). In this paper, we focus only on interactions at the core of the MCDA process. 
The first workshop in Niamey (Niger, 17-20 September 2018) hosted 47 participants from 21 countries, including consortium members from Europe and Africa, and representatives from hydrological service agencies and emergency management agencies on regional and national levels from 17 countries in West and Central Africa. Main aim was to initiate the co-design process. For MCDA, we carried out the problem structuring steps (Figure 1): a stakeholder analysis (sect. 2.2.4); different interactions to identify fundamentally important objectives of participants (i.e., what the system should achieve; sect. 2.2.5), and to identify system configurations that meet the objectives; sect. 2.2.6). The second workshop in Accra (Ghana, 9-12 April 2019) hosted 48 participants from 21 countries. For the MCDA, we consolidated the list of objectives, and elicited participants' preferences regarding achieving these objectives in small groups (sect. 2.2.8). Additionally, we collected preference data on the importance of objectives from each individual participant with questionnaires. This provided interesting insights into preference formation and changes over time (Kuller et al., in prep.). For the third workshop in Abuja (Nigeria, 10-14 February 2020), the number of participants increased to 58, including representatives from WMO (World Meteorological Organization; https://public.wmo.int/), ECOWAS (Economic Community of West African States; https://www.ecowas.int/), and from 16 West and Central African countries. We discussed main MCDA results. During one of the last online workshops, stakeholders completed a survey, providing some feedback for MCDA.

\subsubsection{Stakeholder analysis}

For the stakeholder analysis (Grimble and Wellard, 1997;Reed et al., 2009), we followed Lienert et al. (2013). The workshop participants filled in a pen and paper questionnaire in French or English, assisted by two experts. The survey was completed in 2.5 hours by 31 participants in 18 groups (for countries). After receiving information, the participants completed two tables, one for identifying key West African organizations involved in producing and operating flood forecast and early warning systems, and one for identifying downstream stakeholders (i.e., "Who might play a role because they use information from such systems in society?"). Each table contained eight tasks: (1) listing key organizations or stakeholders; (2) specifications (e.g., names); (3) their presumed main interests; (4) why they might use the FANFAR system; and (5) appropriate distribution channels. We used a 10 point Likert scale, asking participants to (6) rate the importance of considering each listed stakeholder or organization in the FANFAR co-design process; (7) the presumed influence (power) of each stakeholder for implementing the FANFAR system; and (8) how strongly each stakeholder or organization would be affected by the system (i.e., its level of performance). We cleaned the raw data and categorized stakeholders based on whether they are forecast/alert producers or users, their decisional level, sector, and perceived main interest. More details see Silva Pinto and Lienert (2018).

\subsubsection{Generating objectives and attributes}

290 Generating objectives is key to MCDA (Belton and Stewart, 2002;Eisenführ et al., 2010;Keeney, 1982), since this choice can alter results. Simply asking stakeholders is insufficient, and often too few (Bond et al., 2008;Haag et al., 2019c) or too many objectives are produced; we refer to the guidelines in Marttunen et al. (2019). Our stepwise procedure started at the FANFAR kick off meeting in Sweden and continued in the first two West African workshops (details see Lienert et al., 2020). In the first 
workshop, we split participants into three groups. In the first, individuals used an interactive online survey to first brainstorm, then select objectives from a master list (Haag et al., 2019c). Individuals in the second group used the same procedure in a pen and paper survey assisted by a moderator. The third group used a means-ends network in a moderated group discussion to find consensus objectives (Eisenführ et al., 2010). Each participant (respectively group), ranked and rated objectives according to importance. Objectives were discussed in the plenary and the most important ones chosen by majority vote. Between workshops, we post processed objectives to avoid common mistakes such as double counting and overlaps, or including means objectives (Eisenführ et al., 2010). MCDA objectives are only useful if they discriminate options (system configurations in our case), and we dismissed those not fulfilling this requirement. In the second workshop, we presented a revised list of the 10 most important objectives, including a clear definition of the best and worst possible case for each (see description for attributes in sect. SI-2.4.1). For instance, for the objective "Several languages", the FANFAR system being available in several languages is the best case, and only in English the worst. After discussion, the workshop participants agreed on the final list of objectives as basis for MCDA. To operationalize objectives, attributes (synonym indicators) are required (Eisenführ et al., 2010). These were developed by experts from the FANFAR consortium. In most cases, we constructed attributes from several sub-attributes (sect. 2.2.7). Sub-attributes or attributes were transformed to a value with help of marginal value functions (sect. 2.2.8). They were aggregated to a single total value with the MCDA model (sect. 2.2.9).

\subsubsection{Generating system configurations}

Different plausible FANFAR system configurations were generated in the first workshop, in three moderated group sessions. Two groups used the "Strategy Generation Table" (Gregory et al., 2012b;Howard, 1988), and one "Brainwriting 635" (Paulus and Yang, 2000) combined with "Cadavre Exquis" (write words on a paper, fold and give to next person). The Strategy Generation Table is a systematic procedure that allowed pre-structuring elements of the FANFAR system (e.g., observed variables, models for forecast production, language). The stakeholders chose elements forming suitable system configurations ("strategies") with help of questions such as: "The most easy to use system", or the "Most robust system working well given boundary conditions in West Africa (e.g., internet or power supply problems)". Brainwriting 635 allowed for open, interactive brainstorming, using the same strategies as the other groups. All FANFAR system configurations were discussed in the plenary. As part of post processing, additional technically interesting system configurations were created by FANFAR consortium members. For readers unfamiliar with the methods, we provide details in the Supplementary Information (sect. SI-1.1).

\subsubsection{Predicting performance of each system configuration}

Part of the MCDA input data are scientific predictions (Figure 1), based on estimates or models of the level of achievement for each objective (Eisenführ et al., 2010). We used expert estimates (O'Hagan, 2019) by interviewing FANFAR consortium members in July-August 2019. First, experts developed attributes (sect. 2.2.5), in most cases constructed from sub-attributes. They estimated the outcome of each FANFAR system configuration for each (sub-) attribute, i.e., the likely level of each attribute (e.g., likely operation costs) and gave uncertainty ranges regarding their predictions. For constructed attributes, we 
integrated the predictions of the sub-attributes into one final value using a weighted sum (weights defined by experts; sect. 2.2.8). We aggregated the uncertainty of each sub-attribute into a single uncertainty distribution with 1'000 Monte Carlo simulations. To characterize the resulting aggregated uncertainty, we used a normal distribution with mean (of Monte Carlo simulation), and standard deviation ( $1 / 4$ of the $95 \%$ confidence interval from simulation) as input in the MCDA (sect. 2.2.9).

Example: The objective "High accuracy of information" consists of three sub-attributes: KGE index for 1, 3, and 10 day forecasts (Kling-Gupta Efficiency; Gupta et al., 2009). The KGE is one possible accuracy index for hydrological model evaluation, e.g., to estimate the error of predicted vs. observed values. For each FANFAR system configuration and lead day, the expert estimated the expected KGE. The KGE index number was transformed to a value, ranging from 0 (worst) to 1 (best), with a nonlinear marginal value function, elicited from the expert. We aggregated the lead day values into a single value [0:1] with a weighted sum, where the accuracy of the 1 day forecast received a weight of 0.5 , the 3 day forecast of 0.4 , and 10 day forecast of 0.1. Details for predicting system performance (expected achievement of stakeholder objectives) see sect. SI-2.4.

\subsubsection{Eliciting stakeholder (or expert) preferences}

Marginal value functions. Subjective preferences of stakeholders enter the MCDA model on equal footing to expert predictions (Figure 1). Preference elicitation is an important, sensitive step during which many biases can occur (Montibeller and von Winterfeldt, 2015). It is crucial to follow recommendations (Eisenführ et al., 2010). Marginal value functions convert the attribute levels for each objective (e.g., KGE index for "High accuracy of information") to a common scale ranging from 0 (worst possible achievement of this objective) to 1 (best achievement). This allows integrating different attributes with various units into one model, e.g., the KGE index with operation costs ( $€$ / year), and development time (days). As default, a linear marginal value function can be used. However, nonlinear value functions usually better capture preferences. In FANFAR, most attributes are relatively technical, requiring expert knowledge. We therefore elicited shapes of value functions from experts (sect. 2.2.7; details, including figures of value functions, see sect. SI-2.4.1). For each sub-attribute, we mostly created seven evenly spaced levels (worst, very bad, bad, neutral, good, very good, and best). Experts then assigned attribute numbers (e.g., KGE index for 3 day forecasts) to each level based on their experience. We transformed attribute levels to [0:1] values using linear interpolation between levels. As example, the KGE index ranges from minus infinity (worst case, value 0 ) to 1 (best case, value 1; Table SI-8). For attributes consisting of sub-attributes, we elicited a nonlinear marginal value function for each sub-attribute (Figure SI-5), allowing aggregation into one single value. Because we already used elicited nonlinear value functions to construct the composite attribute, we used a linear value function for these in the MCDA (sect. 2.2.9).

Weights. In the second FANFAR workshop, we elicited the weights by dividing participants into five groups according to language (French F, English E) and professional background (Emergency Managers EM, Hydrologists HY). The two French

355 speaking groups used the Swing method (Eisenführ et al., 2010): eight emergency managers (group ID: G1A_EM_F, where G1A = group), and 11 hydrologists (two sub-groups, G2A_HY_F, G2B_HY_F). The two English speaking groups used an adaptation of Simos' revised card procedure (Figueira and Roy, 2002;Pictet and Bollinger, 2008), hereafter Simos card: 14 
hydrologists (G3A_HY_E), and three emergency managers (G4A_EM_E). We separately elicited weights from three AGRHYMET experts with Simos card method (G5A_AGRHYMET). Stakeholders can be uncertain about their preferences, or groups may disagree. For Swing, we avoided forcing participants to reach group consensus and encouraged discussing diverging opinions. This resulted in a range of the stakeholders' weight preferences. We took the mean as main weight and considered strong deviations (difference in weights $>0.2$ compared to mean) in later sensitivity analyses (sect. 2.2.10). For Simos' card procedure, two additional weight sets were used, resulting from eliciting a range for one variable. The moderator recorded important comments to inform the sensitivity analyses (Table SI-3). In the group of French speaking hydrologists, two diverging preference sets emerged from the start, which we analyzed separately (G2A, G2B). For interested readers, we give details of these standard MCDA weight elicitation procedures (sect. SI-1.2). To check for the validity of the additive aggregation model (sect. 2.2.9), we shortly discussed implications in the weight elicitation sessions using elicitation procedures from our earlier work (Haag et al., 2019a;Zheng et al., 2016).

\subsubsection{MCDA model integrating predictions and preferences}

The MCDA model integrates expert predictions with stakeholder preferences. An aggregation model is used to calculate the total value of each alternative (i.e., FANFAR system configuration; Eisenführ et al., 2010). A finite set of alternatives $A=$ $\{a, b, \ldots\}$ are evaluated regarding the predicted outcomes on every objective (respectively attribute). We denote the predicted outcomes (sect. 2.2.7) as $x_{a}=\left(x_{a, 1}, \ldots, x_{a, n}\right)$, with $x_{a, i}$ being the level of an attribute $i$ that measures a predicted consequence of system configuration $a($ or $b, c, \ldots)$. The total value $v\left(x_{a}\right)$ of system configuration $a$ is calculated with a multi-attribute

value function, $v\left(x_{a, 1}, \ldots, x_{a, n}, \Theta\right)$. The resulting total value $v\left(x_{a}\right)$ of each system configuration lies between 0 (all objectives achieve only the worst level) and 1 (all objectives are on the best attribute level that can be achieved given the defined attribute ranges). A rational decision maker would choose the configuration with the highest value. Most commonly, an additive model based on marginal value functions is used, as in Eq. (1), but non-additive models as in Eq. (3) are also possible:

$v\left(x_{1}, x_{2}, \ldots, x_{n}, \Theta\right)=\sum_{i=1}^{n} w_{i} \cdot v_{i}\left(x_{i}, \theta\right)$

380 with parameters $\Theta=\left(w_{1}, \ldots, w_{n}, \theta\right)$, where $w_{i}$ is the weight of attribute $i$, with $0 \leq w_{i} \leq 1$, and $\sum_{\boldsymbol{i}=\mathbf{1}}^{n} \boldsymbol{w}_{\boldsymbol{i}}=\mathbf{1}$, and where $v_{i}\left(x_{i}, \theta\right)$ is the value for the predicted consequence $x_{i}$ of attribute $i$ of system configuration $a$. This value is inferred with help of the marginal value function (sect. 2.2.8).

While easy to understand, the additive model entails strong assumptions, e.g., that objectives are preferentially independent (Eisenführ et al., 2010). Increasing evidence indicates that many stakeholders do not agree with model implications (Haag et 385 al., 2019a;Reichert et al., 2019;Zheng et al., 2016). Additive aggregation implies that good performance on one objective can fully compensate for poor performance on another. In the FANFAR weight elicitation sessions, we asked stakeholders, using 
some examples, whether they agree with objectives being preferentially independent, and as consequence with the full compensatory effect. In all five groups this was not the case. We used a non-additive model with less strict requirements, the weighted power mean with an additional parameter $\gamma$ that determines the degree of non-compensation, see Eq. (3):

If $\gamma=1$, we are back to the additive model in Eq. (1). We used a value for $\gamma=0.2$, based on input from stakeholders (sect. 2.2.8), which is closer to a weighted geometric mean $(\gamma \rightarrow 0)$. We shortly explain and visualize implications of the power mean in sect. SI-1.3. For further details we refer to (Haag et al., 2019b).

We calculated MCDA results in our new open source software "ValueDecisions" (Haag et al., subm.). ValueDecisions is based on the software and programming language R (R Core Team, 2018), earlier R scripts developed in our group (e.g., Haag et al., 2019b), and R “utility” package (Reichert et al., 2013). R scripts were rendered as web application for ValueDecisions with the "shiny" package (Shiny, 2020) Additional analyses were implemented directly in R: aggregating uncertainty of sub-attributes, weight visualization, and statistical analysis of sensitivity analyses.

\subsubsection{Uncertainty of predictions and preferences}

Uncertainty of predictions: Probability theory is used in MAVT (Reichert et al., 2015). We defined uncertainty distributions from expert predictions for each attribute (sect. 2.2.7). We calculated aggregated values of each system configuration across all objectives (sect. 2.2.9), drawing randomly from the attributes' uncertainty distributions in 1'000 Monte Carlo simulation runs. We analyzed rank frequencies: how many times in 1'000 runs each FANFAR system configuration achieved each rank.

Sensitivity analyses of aggregation model and stakeholder preferences: Local sensitivity analyses are commonly used to check the sensitivity of MCDA results to diverging preferences (e.g., Eisenführ et al., 2010;Zheng et al., 2016;Haag et al., subm.). We checked the sensitivity of MCDA results to other aggregation models and changed weights. We used setting S0 as default, and compared results with those of a separate MCDA for each new setting with changed preference input parameters (settings are summarized in the Results, Table 3; details see sect. SI-1.4). For each setting, we compared mean ranks of FANFAR system configurations from 1'000 Monte Carlo simulation runs with those of the default MCDA (S0) using the nonparametric Kendall's $\tau$ correlation coefficient (Kendall, 1938) to measure rank reversals (as in Zheng et al., 2016). To test implications of the aggregation model (sect. 2.2.9), we recalculated the MCDA for other reasonable models (Haag et al., 2019a; settings S11-S14; Table 3). For weights, the weight of one objective is changed, while the ratios of all other weights are kept constant, and renormalized so that the sum of weights remains 1. For a thorough method explanation we refer to Eisenführ et al. (2010) and give some insight for readers not familiar with MCDA in sect. SI-1.4. Consistency checks during weight elici415 tation with the French speaking emergency managers (G1A) revealed an inconsistency, which resulted in strongly different weights (Figure SI-3). We tested their effect on results in sensitivity analysis S21 (Table 3). For Swing weight elicitation, workshop participants stated ranges. We tested the sensitivity of results if the difference between the maximum or minimum 
weight from the average exceeded $\Delta=0.02$ (S22). Similarly, for Simos' card method, we tested alternative weight sets resulting from ranges (S23). It is common to test other interesting objectives by doubling the elicited weight. We did this for "Several languages", because its importance might have been underestimated (S31).

Cost-benefit visualizations are an additional way to check robustness of results (e.g., Liu et al., 2019). This visual analysis is based on the resulting MCDA, including stakeholders' preferences. We did this, using standard setting S0 without prediction uncertainty (Table 3). For reasons of space, we refer to sect. SI-2.9.

\subsubsection{Discuss results with stakeholders, feedback}

425 We presented and discussed preliminary MCDA results with stakeholders in the third workshop. Because the fourth workshop had to be carried out online, we were not able to thoroughly discuss results. However, we assessed stakeholder perceived satisfaction with FANFAR system performance during the 2020 rainy season with an online survey to answer following questions for each objective: (a) How much does FANFAR currently fulfill this objective? (b) Would you use the FANFAR system in the future if it remains as is? (c) What is the minimum acceptable to you? This means: below which level would you NOT use the FANFAR system? (details see sect. SI-1.5). The survey was filled out by 12 participants, resulting for our 10 objectives in $10 \times 12=120$ responses to each question.

\section{Results}

Here, we focus on the MCDA results, ordered as in the Methods section (sect. 2.2). This provides answers to the practical research question (RQA). Based on these MCDA results, we address the other research questions in the Discussion.

\section{$435 \quad 3.1 \quad$ Stakeholder analysis}

Of 249 stakeholders listed by workshop participants, 68 distinct types remained after data cleaning (details see Silva Pinto and Lienert, 2018). Stakeholders that were perceived to have high influence and also potentially being highly affected by the FANFAR system were national entities for disaster management, water resources, and infrastructure, who were already well represented in the co-design process (details Table SI-4). Several specific organizations were also perceived as highly important and affected, such as the "Autorité du Bassin de la Volta" (ABV), who participated in workshops, and AGRHYMET, an organization representing 13 West African states and consortium member. Other important/affected parties were mainly stakeholders receiving flood forecasts and alerts such as NGO's, electricity utilities, dam managers, and the agricultural sector. The Red Cross and environmental protection agencies were perceived to have slightly lower importance/affectedness, among others. Civil society (e.g., communities) would be strongly affected, but have limited decisional influence on developing the

445 FANFAR system. In contrast, the media, industry, and commerce were perceived to have more influence, but would not be strongly affected. Such outlier stakeholders could potentially provide a different view to the FANFAR system. 


\subsection{Objectives and attributes}

The objectives covered a broad range of issues that the stakeholders considered as fundamentally important in view of a Good flood forecast and alert system for West Africa (objectives, attributes, and system configurations are given in Italics hereafter;

450 Figure 2). Several objectives concerned quality requirements for the forecasted flood information, grouped under High information accuracy and clarity, and aspects of Good information access by users such as accounting for language diversity. Aspects of Low costs and longer term High sustainability were also important, such as Skillful human resources available in West Africa, capable of maintaining, operating, and accessing the system. Each objective is characterized by an attribute, for operationalizing the achievement of objectives (Figure 2). Details of attribute calculations are given in sect. SI-2.4.

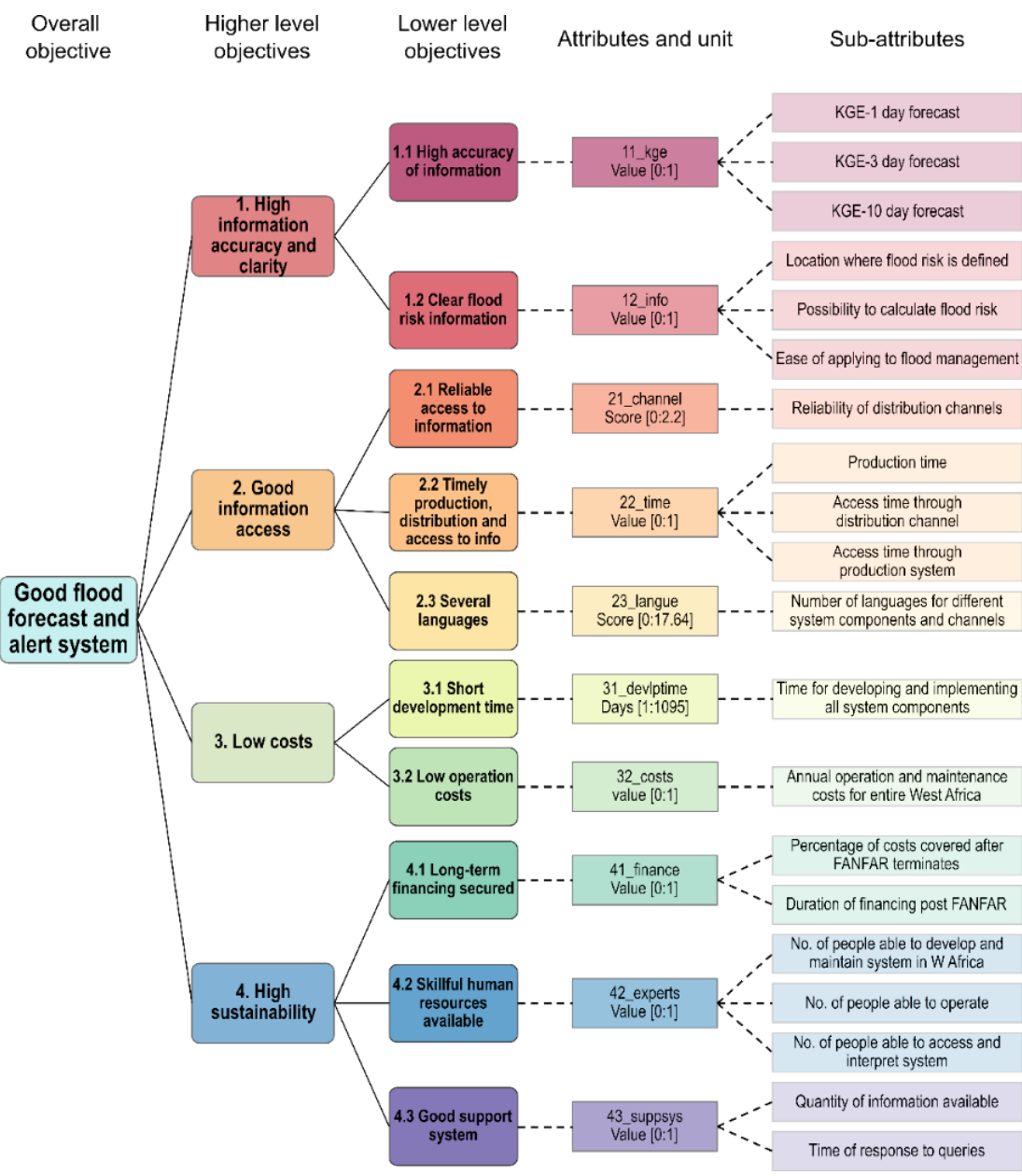

Figure 2. Objectives hierarchy. From left to right: overall objective, four higher level fundamental objectives, 10 lower level fundamental objectives and corresponding attributes, attributes' unit (usually a value) and range [square brackets], from worst (usually value $=0$ ) to best (usually value $=1$ ). Most attributes were constructed from several sub-attributes (far right). 


\subsection{FANFAR system configurations}

Stakeholders generated six system configurations (b to g; Table 2) in workshop sessions. Experts of the FANFAR consortium developed five configurations ( $\mathrm{h}$ to $\mathrm{k}$ ) to cover important technical aspects such as using more refined hydrological models, e.g., redelineation and recalibration of the World Wide HYPE model to West Africa (Andersson et al., 2020b), and including earth observations from satellites. Configurations were constructed in separate sessions with experts from AGRHYMET for the forecast production system, and with stakeholders for the user interface IVP (Interactive Visualization Portal). They were combined to form plausible combinations of various FANFAR system elements (summary of important features in Table 2; for all system elements see Table SI-6 and Table SI-7). Configuration $a$ _Fast-dev represents roughly the state of the first version of the FANFAR system, when stakeholders started experimentation and giving feedback in the first workshop.

Table 2. Overview of 11 FANFAR system configurations. Selected main characteristics: recent hydrological observation data types (HydObs; WL: water level, Q: river discharge, EO: Earth Observations) \& meteorological input/forcing data (MetF; HydroGFD; HydroGFD3 (Berg et al., 2020; improved version); HydroGFD-WA: HydroGFD2 adjusted by West African meteorological observations; Am: American meteorological forecasts (e.g., GFS); Ens: ECMWF ensemble meteorological forecasts); hydrological models (WWH: World-Wide HYPE); forecast output variables (Q: river discharge; WL: water level, P: precipitation; E: evaporation; SM: soil moisture, WQ: water quality); data download (Excel: table for selected station); distribution channels (Web: web visualization; H-TEP: login to H-TEP to download data; FTP: FANFAR and national FTP; API: Application Programming Interface; SoMed:

475 Social Media e.g., WhatsApp; ConMed: conventional media e.g., radio, TV; Tradit: traditional word of mouth) \& automatization (Automatic: automatic push of data to distribution channels; Manual: automatic processing with manual control of distribution by operator); flood hazard reference threshold types (RP Sim: return period based on simulations; RP Obs: return periods based on observations at gauged locations; HistY: selected historic year; Local: user defined thresholds for specific location); language of user interface (En: English; Fr: French; Pt: Portuguese; Ar: Arabic).

\begin{tabular}{|c|c|c|c|c|c|c|c|c|}
\hline ID & Configuration & $\begin{array}{l}\text { Hydrological ob- } \\
\text { servations \& me- } \\
\text { teorological forc- } \\
\text { ing }\end{array}$ & $\begin{array}{l}\text { Hydro- } \\
\text { logical } \\
\text { models }\end{array}$ & $\begin{array}{l}\text { Forecast } \\
\text { output } \\
\text { variables }\end{array}$ & $\begin{array}{l}\text { Data } \\
\text { down- } \\
\text { load }\end{array}$ & $\begin{array}{l}\text { Distribution chan- } \\
\text { nels \& automatiza- } \\
\text { tion }\end{array}$ & $\begin{array}{l}\text { Flood } \\
\text { hazard } \\
\text { thresh- } \\
\text { olds }\end{array}$ & $\begin{array}{l}\text { Lan- } \\
\text { guage }\end{array}$ \\
\hline $\begin{array}{l}\text { a_Fast } \\
-\mathrm{dev}\end{array}$ & $\begin{array}{l}\text { Least resources for devel- } \\
\text { opment: no new features, } \\
\text { status quo }\end{array}$ & $\begin{array}{l}\text { HydObs: none; } \\
\text { MetF: Hy- } \\
\text { droGFD2 }\end{array}$ & $\begin{array}{l}\text { Niger } \\
\text { HYPE }\end{array}$ & $\mathrm{Q}$ & None & Web; Aut & RP Sim & En \\
\hline $\begin{array}{l}\text { b_Res } \\
\text {-user }\end{array}$ & $\begin{array}{l}\text { Least resources for users } \\
\text { (e.g., skilled personnel, } \\
\text { stable internet and power) }\end{array}$ & $\begin{array}{l}\text { HydObs: in situ } \\
\text { WL, Q; MetF: } \\
\text { HydroGFD3 }\end{array}$ & WWH & $\begin{array}{l}\mathrm{Q}, \mathrm{WL}, \\
\mathrm{P}, \mathrm{E}, \mathrm{SM}\end{array}$ & $\begin{array}{l}\text { Excel, } \\
\text { maps, } \\
\text { graphs }\end{array}$ & $\begin{array}{l}\text { Web, H-TEP, SMS, } \\
\text { Email, SoMed, Con- } \\
\text { Med, Tradit; Manual }\end{array}$ & $\begin{array}{l}\text { RP Sim, } \\
\text { RP Obs, } \\
\text { HistY, } \\
\text { Local }\end{array}$ & $\begin{array}{l}\text { En, } \\
\mathrm{Fr}, \mathrm{Pt}, \\
\mathrm{Ar}\end{array}$ \\
\hline $\begin{array}{l}\text { c_Eas } \\
\text { y-use }\end{array}$ & $\begin{array}{l}\text { Most easy to use for pro- } \\
\text { ducing and interpreting } \\
\text { forecasts and alerts }\end{array}$ & $\begin{array}{l}\text { HydObs: EO WL; } \\
\text { MetF: Hy- } \\
\text { droGFD2 }\end{array}$ & $\begin{array}{l}\text { Niger } \\
\text { HYPE }\end{array}$ & $\begin{array}{l}\mathrm{Q}, \mathrm{WL}, \\
\mathrm{P}, \mathrm{E}\end{array}$ & $\begin{array}{l}\text { Excel, } \\
\text { graphs }\end{array}$ & $\begin{array}{l}\text { Web, SMS, SoMed, } \\
\text { ConMed, Tradit; Au- } \\
\text { tomatic }\end{array}$ & $\begin{array}{l}\text { RP Sim, } \\
\text { HistY }\end{array}$ & $\begin{array}{l}\text { En, } \\
\text { Fr, Pt }\end{array}$ \\
\hline
\end{tabular}


d_Fast Fastest system for produc- HydObs: EO WL; Niger Q

ing and distributing fore- MetF: Hy-

casts and alerts

droGFD2

e_Con Highest consensus: system HydObs: in situ

sent elements that West African WL, Q, EO WL;

stakeholders mostly agreed MetF: Hydro-

on

GFD-WA, Am,

Ens

f_Ro- Most robust in West Af-

bust rica: works despite prob-

lems in e.g., data collec-

tion

g_At- Most attractive in West

tractv Africa: many desired fea-

e

tures, similar to $h \_$Equipp,

but simpler distribution

GFD-WA, Am,

Ens

h_Equ Fully equipped: all system HydObs: in situ

ipp elements, except recalibrated HYPE models

WL, Q, EO WL;

MetF: Hydro-

GFD-WA, Am,

Ens

i_Cal- Recalibrated HYPE mod- HydObs: none;

ibr els

MetF: Hy-

droGFD2

j_Cal- Recalibrated HYPE mod-

EO els and EO data

HydObs: EO WL;

MetF: Hy-

droGFD2

k_Cal Recalibrated HYPE mod- HydObs: in situ

-EO- els and EO data and in situ WL, Q, EO WL;

situ data
MetF: Hy-

droGFD2
HYPE

None Web, SMS, Email, RP Sim En

SoMed, ConMed,

Tradit; Automatic

Niger Q, WL, Excel, Web, H-TEP, SMS, RP Sim, En, HYPE, P, E, SM maps, Email, SoMed, Con- HistY Fr, Pt

WWH graphs Med, Tradit; Manual 


\subsection{Predicted performance of each system configuration}

Based on expert predictions but excluding stakeholder preferences, no FANFAR system configuration achieved the best level of all objectives (Figure 3; details see sect. SI-2.4, raw input data for MCDA modelling Table SI-30). This illustrates the impossibility to design a perfect system, given the inherent trade-offs between achieving objectives. For instance, the status quo pre-operational system configuration $a_{-}$Fast-dev achieved the highest values for objective 31_short development time, and 32_costs, but scored low on many others such as accurate, clear, reliable, and timely information. Configurations achieving high levels for objectives of High information accuracy and clarity, inevitably need longer development time and have higher costs. Therefore, it is not possible to clearly determine the "best" configuration based on only the predicted performance (Figure 3). We require input from stakeholders concerning which objectives are most important (sect. 3.5, sect. 3.6).

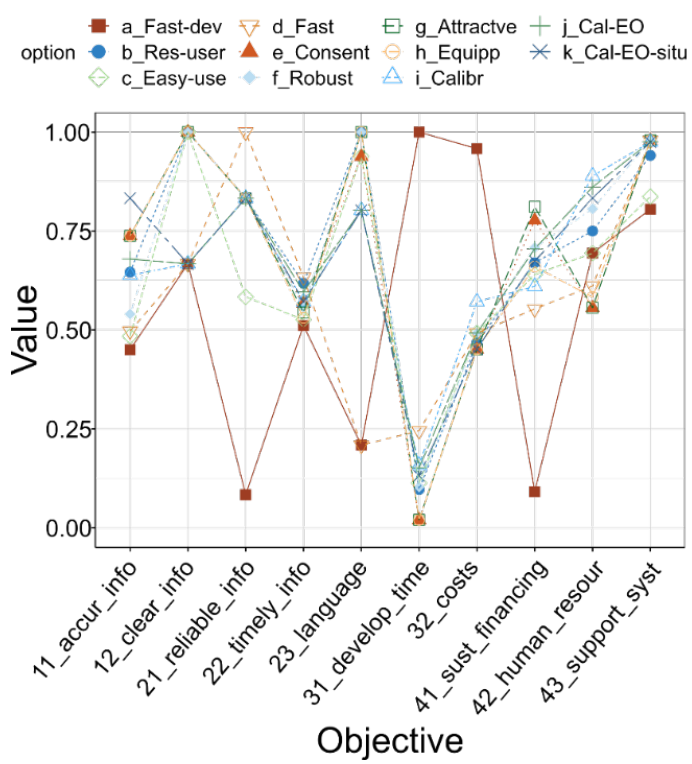

490 Figure 3. Predicted value (y-axis) of 11 FANFAR system configurations (a-k; symbols) for 10 objectives (x-axis), based on expert predictions, but not including stakeholder preferences. Value 1: this system configuration achieved the best level of this objective; 0: configuration achieved the worst level, given the ranges of the underlying attributes (i.e., it is a relative scaling from best to worst).

\subsection{Stakeholder preferences}

The elicited weights $(w)$ for the four higher level objectives were similar for all groups ( $w=$ total bar length; Figure 4$)$, except those of the French speaking emergency managers (G1A). These gave a high weight ( $w=0.25)$ to 3. Low costs, which was least important for the others (0.1-0.12). G1A reasoned that all four higher level objectives are equally important in emergency situations with a connected chain of events. In contrast, the higher level objectives 1 . High information accuracy and clarity, and 2. Good information access were generally regarded as most important by the other groups. There were some notable differences in importance of lower level objectives. Again, the French speaking emergency managers (G1A) were exceptional in assigning much lower weights to objectives they considered unimportant (objectives $23,31,41$, and 43 ). They argued that 
the goal in emergencies is to save lives, and FANFAR system development should focus on achieving fast access to flood alerts (22_timely_info; 0.21) and on personnel that can deal with this information (42_human_resour; 0.25). The weight sets in the other groups were overall more balanced (details see sect. SI-2.6). There were different levels of consensus about weights within a group, reflected in the length of the error bars (Figure 4).

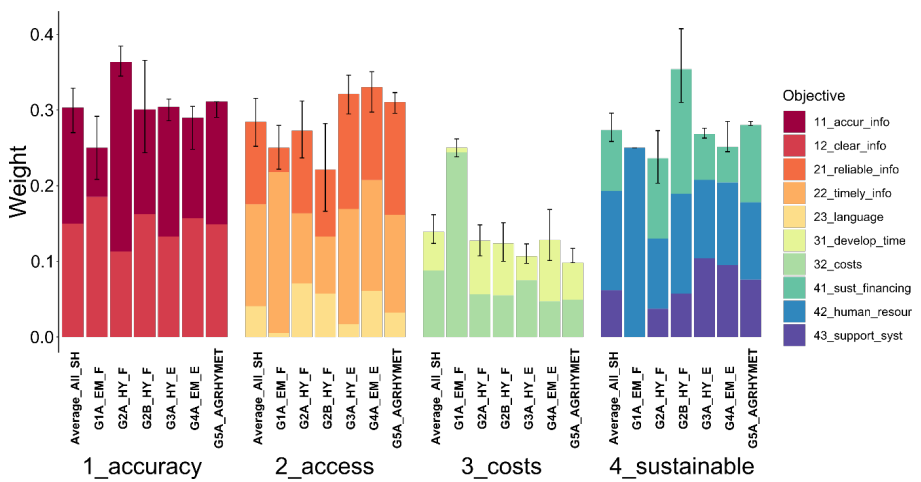

Figure 4. Weights (y-axis) assigned to higher level objectives (blocks, 1_accuracy, 2_access, etc.) colored by weights of lower level objectives (11_accur_info, 12_clear_info, etc.), averaged over all six stakeholder groups (Average_All_SH), and for each group (G1A_EM_F, G2A_- HY_F, etc; x-axis). Error bars: uncertainty of elicited preference statements, i.e., the sum of uncertainties of all lower level objectives within the branch of the respective higher level objective. Per definition all weights of a group sum up to 1.

\subsection{MCDA model results}

No FANFAR system configuration clearly outperformed the others for all stakeholder groups in the standard MCDA (setting S0; Table 3) that did not consider uncertainty (Figure 5; details see Table SI-32; Table SI-33). The early stage configuration at the beginning of the project $\left(a \_\right.$Fast-dev) achieved lowest total values $(v<0.46)$ and the last rank for all stakeholder groups, except the French speaking emergency managers (group G1A, $v=0.64$, rank 5). This can be attributed to the different weight preferences of G1A. All other configurations generally reached high values for all groups, with only small differences between groups. The total value ranged from $v=0.55$ in the worst case ( $d$ _Fast for G2A) to 0.70 (b_Res-user, G3A). Indeed, this configuration $b \_$Res-user seemed somewhat better than the others, achieving a high value $(v=0.65-0.70)$ for all groups, thus reaching the first rank for all, again with exception of group G1A, for which it still achieved the second rank. For better understanding $[0,1]$ values can be interpreted as percentages, and $b_{-}$Res-user was able to achieve $65-70 \%$ of the ideal case over all objectives in all stakeholder groups. Configurations $f \_R o b u s t, i \_C a l i b r, j \_C a l-E O$, and $k_{-} C a l$-EO-situ also performed well (0.63-0.70) for all groups, while $c_{-} E a s y-u s e$, and $d_{-}$Fast achieved the lowest values (0.55-0.64). 


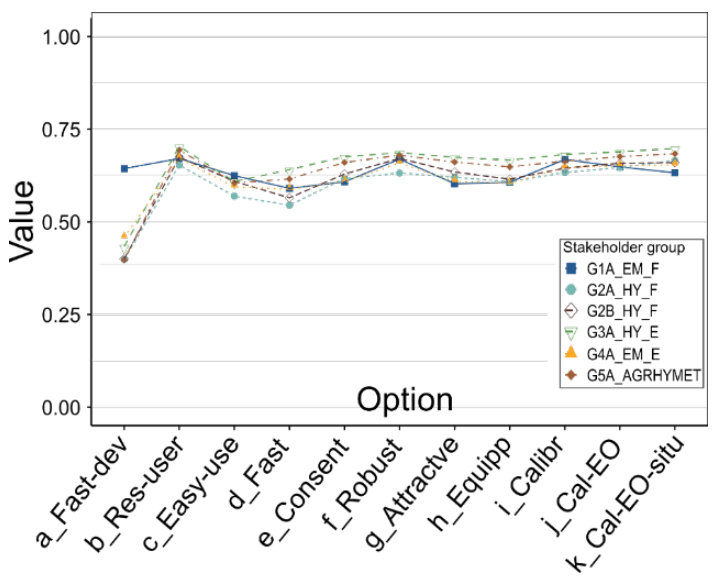

Figure 5. Total aggregated value (y-axis) of 11 FANFAR system configurations (x-axis) for six stakeholder groups (symbols), without uncertainty. Higher values indicate that they better achieves the objectives, given expert predictions and stakeholders' preferences.

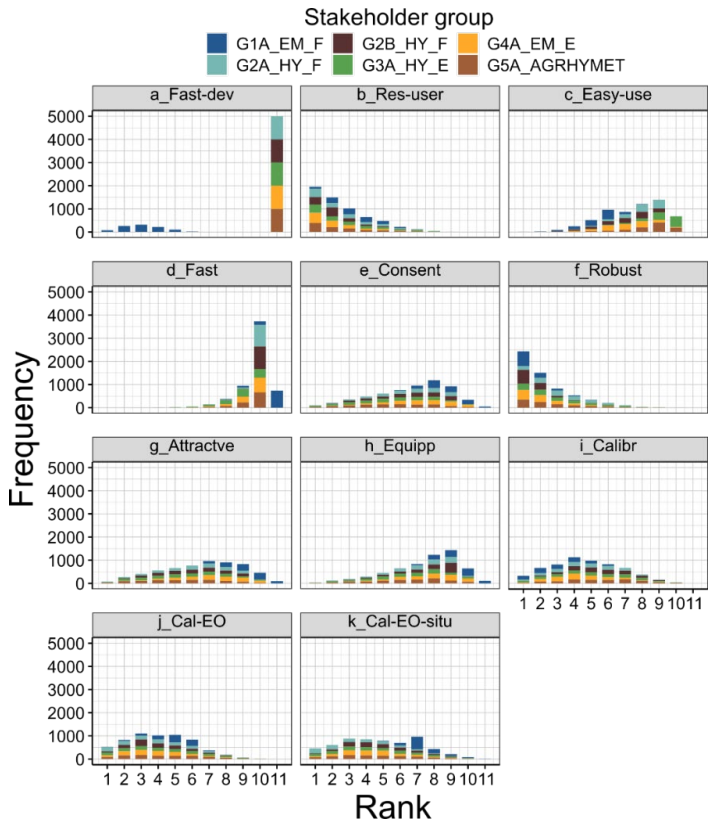

Figure 6. Ranks of 11 FANFAR system configurations including uncertainty of expert predictions. Frequency (y-axis): how often each configuration (blocks, $a \_F a s t-d e v, b \_$Res-user, etc.) achieves rank (1: best rank, 11: worst; $x$-axis) in each model run, for each stakeholder group (stacked bars). 1'000 Monte Carlo simulation runs draw from uncertainty distributions of attribute predictions.

Including uncertainty of the expert predictions in the MCDA with Monte Carlo simulation clarified results. The FANFAR system configurations $b_{-}$Res-user and $f \_$Robust performed well and achieved the highest ranks for all stakeholder groups in 1'000 simulation runs (Figure 6; details Table SI-34). The configurations $i_{-}$Calibr, and $j \_C a l-E O$, achieved good to medium ranks for most groups in most simulations. Poor performance was achieved by configurations $a_{-}$Fast-dev (except group G1A), and d_Fast, which hit the last ranks in most simulation runs. The remaining configurations performed somewhere in between. 


\subsection{Sensitivity analyses of stakeholder preferences}

535 The performance of FANFAR system configurations was not sensitive to most model parameter changes (Table 3). The least changes in rankings occurred between the standard MCDA (S0) and sensitivity analyses testing the extremes of the weight ranges elicited from stakeholders in the workshop (S22-S232; Table 3): Kendall's $\tau$ rank correlations were high, ranging from 0.86 to 1 (identical ranking of all configurations). Doubling the weight of 23_language (S31) hardly impacted the rankings for any stakeholder group. Greater changes occurred using other aggregation models. The difference between our standard MCDA (S0) and changing aggregation models increased, the more the aggregation parameter $\gamma$ increased from 0 (geometric mean; $\mathrm{S} 12)$, over mixture models (S13, S14), to the additive model with $\gamma=1$ (S11). Rank correlations were still relatively high between the additive model and our S0 standard model (0.53-0.86), and importantly, the rankings of the best-performing configurations, $b \_$Res-user and $f$ Robust did not change (details sect. SI-2.8). For other configurations, including $i \_C a l i b r$, there were some greater differences, depending on the group. The greatest changes occurred for an alternative weight set (S21) elicited in the group of French speaking emergency managers (G1A). Interestingly, this set moved the rankings and values of system configurations to those of all other groups, group G1A no longer being an outlier, and e.g., configuration $a \_F a s t-d e v$ clearly performing worst for all groups, also G1A (Figure SI-40). Cost-benefit visualizations confirmed that configurations b_Res-user,f_Robust, and $i \_C a l i b r$ are suitable consensus configurations (provided in sect. SI-2.9 for reasons of space).

Table 3. Results of local sensitivity analyses. Setting S0: default with elicited preferences of stakeholder groups and weighted power mean model, Eq. (3). Setting S11-S14: effect of other aggregation models (varying $\gamma$ ). S21-S22: uncertainty of Swing weights. S231S232: uncertainty of Simos' card method weights. S31: increase (possibly underestimated) weight. S11-S31: all other parameters as S0. Columns G1A to G5A: Kendall's $\tau$ rank correlation coefficient between ranks of configurations in main MCDA (setting S0) and ranks resulting from MCDA using other settings (S11-S31) for stakeholder groups (e.g., group G1A). Column mean: correlation between S0 and average rank over all groups for which analysis was done. Note: S21 was only done for group G1A_E (i.e., mean = group correlation). Kendall's $\tau$ 1: identical ranks; 0: no correlation; -1 : inverse relationship; -: not applicable. Kendall's $\tau$ from 0.81-1.00: underlined, indicating very good agreement between changed setting and S0; $\tau$ from $0.61-8.80$ : dotted underlined.

\begin{tabular}{|c|c|c|c|c|c|c|c|c|}
\hline Setting & Definition & G1A & G2A & G2B & G3A & G4A & G5A & Mean \\
\hline \multirow[t]{2}{*}{ S0 } & Default. MCDA for all six stakeholder groups; & & & & & & & \\
\hline & $\gamma=0.2$; see Methods, eq. (3) & & & & & & & \\
\hline S11 & Additive model all groups; $\gamma=1$ & $\underline{0.86}$ & 0.64 & 0.60 & 0.64 & 0.53 & 0.75 & 0.67 \\
\hline S12 & Weighted geometric mean all groups; $\gamma \rightarrow 0$ & $\underline{0.96}$ & 0.78 & $\underline{0.93}$ & $\underline{1.00}$ & $\underline{0.82}$ & $\underline{0.93}$ & $\underline{0.90}$ \\
\hline S13 & Mixture model; $\gamma=0.5$ & $\underline{0.93}$ & 0.78 & 0.67 & 0.75 & 0.75 & 0.75 & 0.77 \\
\hline S14 & Weighted power mean; $\gamma=0.8$ & $\underline{0.89}$ & 0.67 & 0.64 & 0.64 & 0.53 & 0.75 & 0.69 \\
\hline S 21 & Alternative weight set for group G1A & 0.31 & - & - & - & - & - & 0.31 \\
\hline S22_11_min & $\begin{array}{l}\text { Weight ranges with } \Delta>0.02 \text { from average } \\
\text { weight for 11_accur_info; minimum weight }\end{array}$ & $\underline{0.96}$ & - & $\underline{0.96}$ & - & - & - & $\underline{0.96}$ \\
\hline S22_11_max & 11_accur_info; maximum weight & - & - & $\underline{1.00}$ & - & - & - & $\underline{1.00}$ \\
\hline
\end{tabular}


S22_12_min Weight ranges with $\Delta>0.02$ from average $\begin{array}{llllllll}- & - & \underline{1.00} & - & - & - & \underline{\mathbf{1 . 0 0}}\end{array}$ weight for 12_clear_info; minimum weight

S22_12_max 12_clear_info; maximum weight $\underline{0.86}$ Alternative weights resulting from ranges as$\underline{0.86}-\underline{0.86}$ $-\quad-$ $-\quad \underline{0.86}$ signed to $Z$ min

S232 Alternative weights resulting from ranges as-

$-\quad-$ signed to $\mathrm{Z}$ max

\subsection{Stakeholders' perceived satisfaction with the FANFAR system}

Most respondents perceived the current performance as sufficient for all objectives, based on the direct question about future use of the current FANFAR system (b), and the inferred difference ( $c-a)$ between how much the current system fulfills the respective objective (a) and the minimum acceptable level (c). Across all objectives, 79 responses were positive, 16 negative, and $25 \mathrm{did}$ not answer question b. For the most important objective, 11_accur_info, all respondents would use the current system in future (Figure 7). However, four (of 12) respondents indicated that the system does not currently meet their minimum acceptable performance requirements. This result is representative of the results for all objectives (details see sect. SI-2.10).

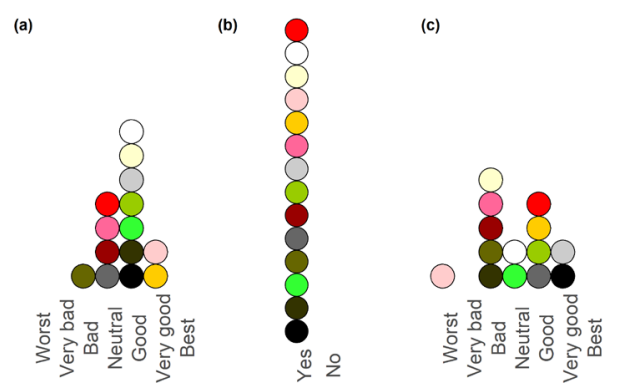

565 Figure 7. Stakeholder perceived satisfaction with the performance of the FANFAR system during the 2020 rainy season for objective 11_accur_info. Questions: (a) How much does the FANFAR system currently fulfil this objective? (b) Would you use the system in the future if it remains as is? (c) What is the minimum acceptable to you? Colored dots represent unique respondents $(\mathrm{N}=12)$.

\section{Discussion}

The discussion follows the research questions (sect. 1.3). RQA was confirmed: we found a robust FANFAR system configuration despite large uncertainty and different stakeholder preferences (sect. 4.1). We discuss our experience with MCDA related to uncertainty and eliciting stakeholder preferences in sect. 4.1.2. RQB was partly confirmed: early problem structuring focusing on objectives helped FANFAR system development (sect. 4.2). However, system developers needed MCDA weight elicitation asking for trade-offs to set priorities in the middle of the project, and full MCDA results to conclude that priorities were robust. In RQC we analyzed the MCDA process for guiding large transdisciplinary projects (sect. 4.3), following the 
proposed framework (sect. 2.1.1; Table 1). For step 1, co-design and joint problem framing, various requirements were met by the FANFAR project, but could not be attributed to MCDA (sect. 4.3.1). However, if MCDA is broadly understood as a participative process that includes problem structuring, it can be very suitable for identifying stakeholders and guiding them to focus on objectives for achieving a joint boundary object, the FANFAR system. For step 2, co-production of new knowledge, MCDA is appropriate (sect. 4.3.2). Core strengths of MCDA are that it can integrate scientific knowledge from different disciplines by providing a consistent framework and can handle uncertainty. MCDA invites stakeholders to clearly formulate their preferences, and identifies consensus configurations. Step 3, co-disseminating knowledge and evaluation, can only partly be achieved by MCDA (sect. 4.3.3). MCDA produces concrete, prescriptive knowledge: a suitable configuration of the FANFAR system. However, MCDA is not appropriate for other aspects such as producing and implementing real-world solutions, or impact evaluation. Main insights and recommendations are summarized in Table 4 and in the Conclusions (RQD, sect. 5).

\subsection{Finding robust FANFAR system configurations (RQA)}

\subsubsection{Main MCDA results}

As the most important practical result to RQA, we could identify three FANFAR system configurations that had a good overall performance (Figure 5). This would be difficult to achieve without MCDA, given the uncertainty of expert estimates and the model (Figure 6). Moreover, trade-offs between objectives had to be made (Figure 3), and stakeholders had different preferences concerning the importance of objectives (Figure 4). One well-performing configuration, $b \_$Res-user, was created by stakeholders in the first FANFAR workshop. They chose system components requiring the least resources for West Africa such as skilled personnel, good internet connection, or stable power supply (Table 2). Similarly, configuration $f$ Robust was created by stakeholders to reliably work under difficult West African conditions related to collecting in situ data and distributing information through a wide range of channels. The third configuration $i_{-}$Calibr was created by FANFAR consortium members focusing on using refined HYPE models (e.g., with adjusted delineation and parameter calibration; Andersson et al., 2020b), but not including earth observation or in situ data (included in configuration $j$ and $k$; Table 2). All three best configurations achieved $63-70 \%$ of all objectives in all stakeholder groups. We consider this a very good value, given the existing trade-offs. These configurations also emerged as robust consensus from (i) including the uncertainty of expert predictions with Monte Carlo simulation (Figure 6); (ii) sensitivity analyses of model assumptions and changing stakeholders' weight prefer-

600 ences (Table 3); and (iii) dominance checks in cost-benefit visualizations (sect. SI-2.9). Interestingly, none of these three configurations incorporate more advanced system features. Hence, a flood forecast and alert system that meets the preferences of the West African stakeholders primarily needs to work accurately and reliably under difficult conditions in West Africa.

\subsubsection{Dealing with uncertainty of predictions, preferences, and model assumptions}

Attributes operationalize objectives (Eisenführ et al., 2010). Seemingly trivial, this is often challenging. We illustrated this for $60511 \_k g e$, constructed from the KGE index for 1,3, and 10 day forecasts to measure achieving 1.1 High accuracy of information 
(sect. 2.2.7). The uncertainty of expert predictions was relatively large for some attributes (e.g., $11 \_k g e, 22 \_t i m e$, or $42 \_e x$ perts), but small to inexistent for others (12_info, 23_langue; Figure SI-30). The resulting overall uncertainty affected the results less than might be expected (Figure SI-35).

The weights indicate that most groups preferred a system producing accurate, clear, and reliable information, reaching recipients well before floods (11_accur_info; 12_clear_info; 21_reliable_info; 22_timely info; Figure 4), and West African countries need the capability to handle this information (42_human_resour). We captured differences within groups with uncertainty ranges or separate preference sets (e.g., subgroups G1A, G2B; sect. SI-1.2.3; sect. SI-2.6). The French speaking emergency managers (G1A) had different preferences compared to all others. All groups regarded several languages as unimportant in weight elicitation, despite emphasizing in plenary discussions that language diversity is crucial. When asked to make tradeoffs between accuracy and language, they were willing to give up the latter. They were also willing to trade-off higher operation and maintenance costs (except group G1A) and development time in return for receiving a functioning, precise system.

Including the uncertainty of expert estimates and stakeholder preferences in MCDA can blur results. For FANFAR, MultiAttribute Value Theory and local sensitivity analyses (e.g., as Zheng et al., 2016) enabled identifying configurations suiting all stakeholder groups. Including the uncertainty of predictions helped to better distinguish between performances of configurations (Figure 6), compared to the standard analysis without uncertainty (Figure 5). Configurations b_Res-user and $f_{-}$Robust consistently achieved the first ranks in 1'000 simulation runs, and e.g., $i$ Calibr good to medium ranks. However, some configurations such as $k_{-} C a l-E O$-situ, ranked last in numerous runs (Figure 6), despite achieving good values when uncertainty was disregarded (0.63-0.70; Table SI-33). Ranking last in most runs, a_Fast- and d_Fast_dev would be an imprudent choice. Local sensitivity analyses confirmed that configurations b_Res-user, $f_{-}$Robust, and $i_{-}$Calibr are robust choices. Changing stakeholder preferences hardly changed MCDA results compared to our standard model (S0; Table 3). Doubling the weight of 23_language (S31) did not affect results in any group, thus avoiding costly translations as priority. Operation and maintenance costs would have been another candidate for doubling the weight, but was covered by the high weight of group G1A_EM_F. In this group, sensitivity analyses on weight ranges given by group participants with a different opinion (S21; Table 3) changed the results so that they aligned with results of the other stakeholder groups. This increases our confidence that the three proposed configurations are a good consensus. Moreover, the additive MCDA aggregation model (Eq. (1); sect. 2.2.9) impacted the rankings of the FANFAR system configurations (Table 3). As standard model, we assumed non-additive aggregation (Eq. 3 ), which is relatively close to a weighted geometric mean model, based on feedback in the weight elicitation sessions. After discussing examples, all groups stated that poor performance on an important objective should not be compensated by good performance on others, a main implication of additive aggregation. This confirms that the additive model can unintentionally violate stakeholder's preferences (e.g., Haag et al., 2019a;Reichert et al., 2019;Zheng et al., 2016). Thus, additive aggregation may not be the best model, despite its popularity in MCDA applications. For FANFAR, sensitivity analyses sufficed to conclude that additive aggregation has an effect, but does not alter rankings of the best configurations. We can thus safely conclude 
that the three proposed FANFAR system configurations are suitable. We emphasize that the FANFAR system was continuously improved throughout the project, also after eliciting stakeholder preferences in the second workshop.

\subsection{Early problem structuring focused FANFAR system development (RQB)}

Early problem structuring steps helped focusing technical system development before MCDA results were available (RQB) This is important for agile development processes, since complex MCDA often takes considerable time to produce solid results. We emphasized objectives, rather than starting with FANFAR system configurations, motivated by "Value focused thinking" (Keeney, 1996). Asking: "What is important when designing a flood forecast and alert system for West Africa?" in the first

workshop allowed system developers to focus on priority objectives. Elicitation of stakeholder preferences in the second workshop further guided system design, e.g., that not all system components needed translation to several languages (sect. 4.1.2). Moreover, designing a flood forecast and alert system is complex (Andersson et al., 2020b;Arheimer et al., 2011;Emerton et al., 2016), with a risk of getting lost in stakeholder discussions about system elements. To avoid this, we included all stakeholder suggestions when creating system configurations. Hydrologists and ICT specialists then aimed at finding best solutions, given the stakeholders' priorities and experts' predictions about system performance. To conclude, early problem structuring was useful, but later weight elicitation was needed to prioritize subsequent FANFAR system development. The MCDA results confirmed the robustness of mid-term priorities, which can be different in each case. We thus recommend doing the entire MCDA to test the sensitivity of results (sect. 4.1.2). The stepwise iterative approach employed here (beginning with key objectives, then focusing on system configurations), was very productive, and would likely be useful also in other projects.

\subsection{Suitability of the MCDA process for guiding large transdisciplinary projects (RQC)}

We discuss research question RQC following the framework for transdisciplinary research (Table 1). We critically evaluate a participatory MCDA process for guiding a large transdisciplinary research project. We focus on aspects that we consider important when carrying out MCDA in a hydrology context. Main points and recommendations are summarized in Table 4.

\subsubsection{Evaluating the co-design step "joint problem framing"}

The MCDA process does not fully meet all requirements of this step. In the FANFAR project, building the collaborative research (or project) team with consortium partners from Europe and West Africa was achieved (step 1a, Table 1), but not by MCDA. Two key West African stakeholders were consortium partners from the start: AGRHYMET (mandated by 13 West African states and ECOWAS to provide e.g., operational flood warnings), and NIHSA (Nigerian Hydrological Services Agency). This follows a decade of collaboration between SMHI and AGRHYMET. Building alliances with regional partners is a transdisciplinary approach identified across projects, and may lead to partnerships in follow-up work (Wuelser et al., 2021). Trust building is crucial (e.g., Lemos and Morehouse, 2005), and AGRHYMET is clearly a bridging organization or knowledge broker (Norstrom et al., 2020; Wuelser et al., 2021) between research and implementation. The FANFAR project was co-led by West African partners and engaged stakeholders in workshops, meeting the principle of creating knowledge 
tailored to specific contexts (Caniglia et al., 2021;Norstrom et al., 2020), but this is not due to MCDA. Similarly, MCDA was not responsible for defining the research questions (step 1b, Table 1), nor the boundary object (step 1c). FANFAR had a concrete boundary object, allowing stakeholders to commit (Jahn et al., 2012): producing an operational flood forecast and alert system. It was in the interest of scientists and stakeholders to achieve this goal, thus helping to overcome the problem of unbalanced ownership (Lang et al., 2012). The FANFAR consortium agreed to use MCDA as integrative methodological framework (1b) for achieving this objective. Literature emphasizes the importance of using methodologically consistent procedures for integrating across scientific disciplines (Lemos and Morehouse, 2005; Mauser et al., 2013; Lang et al., 2012). We regard MCDA as such a useful, stringent, and integrative methodology. Indeed, stakeholder related multi-criteria assessment (i.e., MCDA) was mentioned as one possible methodology to produce transferable knowledge (Wuelser et al., 2021).

Narrowing the perspective to the concrete project in West Africa with local stakeholders, an MCDA process that emphasizes early problem structuring (Marttunen et al., 2017; Rosenhead and Mingers, 2001) can be helpful. Taking practitioners on board from the beginning is crucial (Wuelser et al., 2021), and insufficient legitimacy or underrepresentation of actors is a challenge (Lang et al., 2012). To identify those that should be involved, stakeholder mapping or social network analysis are suitable (Norstrom et al., 2020; Lang et al., 2012). As first step of MCDA, we carried out a stakeholder analysis (step 1a, Table 1). However, in typical MCDA projects, stakeholder analysis was done in only $9 \%$ of 333 reviewed papers (Marttunen et al., 2017). We used relatively simple questionnaires (sect. 2.2.4) to discover who has influence or power, and who is affected by a good or malfunctioning flood forecast and alert system (Grimble and Wellard, 1997;Lienert et al., 2013;Reed et al., 2009). We identified 68 distinct stakeholder types (sect. 3.1). In the workshops, we included hydrology representatives from 17 countries, and key supranational organizations such as AGRHYMET who produce flood information (Table SI-4; details see Silva Pinto and Lienert, 2018). Main receivers of flood information also participated: emergency managers from every country. Thanks to their experience, we integrated the alert dissemination chain in FANFAR and elaborated elements of effective flood early warning systems (Kuller et al., 2021). We also identified missing parties, e.g., agriculture, industry (dam managers, electricity utilities), or humanitarian aid organizations, some of which provided informal feedback on the FANFAR system through social media. We did not invite them because more than 50 participants in workshops is ineffective. Indeed, pluralistic co-production while keeping processes manageable remains a challenge (Norstrom et al., 2020;Lang et al., 2012).

Problem structuring is decisive because MCDA results critically depend on objectives and options (i.e., system configurations Marttunen et al., 2017;Rosenhead and Mingers, 2001). These MCDA steps (Figure 1) were carried out in the first stakeholder workshop (sect. 2.2.5 and 2.2.6). At a specific level, the interactions helped define meaningful, shared goals, and one measure of success (e.g., Norstrom et al., 2020; step 1b, Table 1): to find a FANFAR system configuration that meets objectives that should be achieved by this system. Following "Value focused thinking" (Keeney, 1996), we first generated objectives in small groups using different methods (sect. 2.2.5) to ensure a broad diversity of objectives and avoid the common "group think bias" (Janis, 1972). We are confident that we captured the most important 10 objectives that cover fundamental aims of West African 
stakeholders (Figure 2). Moreover, many environmental applications of MCDA use too many objectives (Marttunen et al., 2018). This is ineffective and burdens MCDA weight elicitation. We excluded some objectives in plenary discussions.

We could not assume that all participants had sufficient technical knowledge to generate system configurations, but aimed to avoid "myopic problem representation", a bias to stick to what one knows (Montibeller and von Winterfeldt, 2015). We find the Strategy Generation Table (Gregory et al., 2012b;Howard, 1988) especially suitable. It pre-structures the process while allowing for creative stakeholder inputs. The context-based principle of co-production includes asking for constraining factors (Norstrom et al., 2020). When creating FANFAR system configurations, it became evident that e.g., frequent power cuts and slow internet in West Africa need consideration. Multi-Attribute Value Theory (Eisenführ et al., 2010) allows later including system configurations (Reichert et al., 2015). The FANFAR consortium created additional configurations to cover technical aspects, e.g., ensemble meteorological forecasts, redelineation and calibration of hydrological models, assimilation of EO water levels and in situ gauge observations from rivers (configurations $h$ to $k$, Table 2; Table SI-6). The status quo system at project start, a_Fast-dev, was also created during post-processing to serve as benchmark. Indeed, it performed poorly for most groups (Figure 5). As summary, the three MCDA steps of stakeholder analysis, creating objectives and system configurations took up a large part of the first West African workshop. They were very helpful for stakeholders to exchange ideas, express their needs and wishes, and develop a common understanding, contributing to the co-design step 1 (Table 4).

Table 4. Summary of MCDA process using conceptual framework for transdisciplinary research (Table 1): (1) co-design, (2) coproduction, and (3) co-dissemination of knowledge. Symbols: +++ strength of MCDA; ++ well possible with MCDA; + possible contribution by MCDA; 0 not achievable by MCDA; * remark. PSM: Problem Structuring Methods; VFT: Value Focused Thinking.

\begin{tabular}{|c|c|c|c|}
\hline ID & Step & MCDA & Remarks and recommendations \\
\hline 1 & Co-design & \multicolumn{2}{|c|}{ Joint problem framing } \\
\hline \multirow[t]{3}{*}{$1 \mathrm{a}$} & Collaborative & 0 & - Include local partners in consortium (knowledge brokers, bridging organizations) \\
\hline & research team & 0 & - Build alliances with regional partners, also for follow-up projects (trust building) \\
\hline & & +++ & - MCDA PSM: stakeholder analysis with simple questionnaires (sect. 2.2.4) \\
\hline \multirow[t]{5}{*}{$1 \mathrm{~b}$} & Research questions, & ++ & - MCDA can help jointly defining research questions if PSM is used \\
\hline & methodological & 0 & - MCDA is less suitable to define project success criteria (but PSM could be used) \\
\hline & framework & +++ & - MCDA provides an integrative methodological framework (sect. 2.2) \\
\hline & & ++ & - MCDA PSM: use VFT for defining shared objectives at lower level (sect. 2.2.5) \\
\hline & & ++ & $\begin{array}{l}\text { - MCDA PSM: use creativity techniques to find diverse, locally adapted solutions } \\
\text { (e.g., strategy building table; sect. 2.2.6); increases common understanding }\end{array}$ \\
\hline $1 \mathrm{c}$ & Boundary object & + & - MCDA PSM could potentially be used for creating boundary object \\
\hline 2 & Co-production & \multicolumn{2}{|c|}{ Conducting integrated research to produce new knowledge; continuous exchange } \\
\hline $2 \mathrm{a}$ & Integrative methods & +++ & - MCDA is a methodologically consistent integrative procedure, but there are others \\
\hline
\end{tabular}




\begin{tabular}{|c|c|c|c|}
\hline ID & Step & MCDA & Remarks and recommendations \\
\hline \multirow{2}{*}{$2 \mathrm{~b}$} & laboration & & disciplines using predictions (sect. 2.2.7) and value functions (sect. 2.2.8) \\
\hline & & & * Not emphasized in reviewed transdisciplinary literature: merits future research \\
\hline
\end{tabular}

Uncertainty

\begin{tabular}{cc} 
Uncertainty & +++ \\
\hline $\mathrm{d}$ Integrate practice & ++ \\
stakeholders & 0 \\
& 0 \\
& +++ \\
secial learning & +++ \\
& +++ \\
& +++ \\
& 0
\end{tabular}

- MCDA can explicitly consider various types of uncertainty (sect. 4.1.2)

* High relevance for projects in earth systems sciences; merits future research

3 Co-dissemination Integrate and disseminate knowledge among research and societal groups, and evaluation

3a Two-dimensional in- $\quad++\quad$ - MCDA: some discussion and revision of results (to find consensus configurations) tegration $\quad+++\quad$ MCDA provides prescriptive knowledge (e.g., suitable system configuration)

0 - MCDA cannot review and analyze other aspects (e.g., governance mechanisms)

\begin{tabular}{llll}
\hline b Targeted products & 0 & $\bullet$ MCDA cannot generate target products (e.g., publications, policy briefs, maps) \\
& 0 & $\bullet$ MCDA cannot implement and scale up knowledge for real-world problem solving \\
& + & $\bullet$ Scientific integration, generalization, and documentation is not specific to MCDA \\
\hline 3c Evaluate societal & + & $\bullet$ MCDA usually does not evaluate societal and scientific impact (but is possible) \\
and scientific impact & 0 & $\bullet$ Mid-term impacts cannot be attributed to MCDA (e.g., uptake, societal effects) \\
& 0 & $\bullet$ MCDA cannot capture longer-term impacts, which are anyway difficult to measure
\end{tabular}

\subsubsection{Evaluating the co-production step "integrated research to produce new knowledge"}

720 Using consistent integrative methods (step 2a, Table 1) and systematic procedures for different bodies of knowledge (Lang et al., 2012;Mauser et al., 2013) is crucial, but seems less visible in literature (Wuelser et al., 2021). Recommendations include generating hazard maps, qualitative system analysis, scenario analysis, and sensitivity or multi-criteria assessments (i.e., MCDA). Applying procedures to identify stakeholders' positions and preferred configurations is beneficial because it involves 
people in creating their future (Wuelser et al., 2021). MCDA clearly helped structuring the co-design process and integrating different types of knowledge: expert estimates of how well each FANFAR system configuration achieves each objective (sect. 3.4) and stakeholders' preferences (sect. 3.5). At each workshop, West African stakeholders experimented with the FANFAR system, tested it in rainy seasons, and provided feedback (see Wuelser et al., 2021), which cannot be attributed to MCDA.

Transdisciplinary projects rely on interdisciplinary collaboration (step 2b, Table 1; Jahn et al., 2012;Lemos and Morehouse, 2005). Methods must allow for consistent integration of scientific evidence from different disciplines to avoid "comparing apples with pears" (Mauser et al., 2013, p. 426). Integrating qualitative data for policy and decision making, and quantitative data required by models can be challenging (Lang et al., 2012). MCDA handles this by transforming attributes of different measurement units (including qualitative scales) to a common scale between 0 (objective not achieved) to 1 (objective fully achieved), using value functions (sect. 2.2.8). In FANFAR, experts from different disciplines provided these estimates: West African and European hydrologists, IT specialists, and decision analysts (sect. SI-2.4.1). MCDA integrates very specific data (predictions about performance of system configurations). Other types of evidence also need integration in transdisciplinary projects, and other methods are available. This area merits future research, given the lack of emphasis in current literature.

"Questions of the uncertainty of the results" (Mauser et al., 2013; p. 428) were emphasized by earth systems scientists for global sustainability, but scarcely addressed by others (step 2c, Table 1). Our MCDA included the uncertainty of expert predictions by eliciting probability distributions for each attribute (sect. SI-2.4.1) and Monte Carlo simulation (sect. 2.2.10). Local sensitivity analyses addressed uncertainty of the model and of stakeholder preferences (sect. 4.1.2; discussed in Reichert et al., 2015). Handling uncertainty in a conceptually valid way is essential for transdisciplinary research in earth systems science.

The importance of integrating practice stakeholders in iterative processes (step 2d, Table 1) was underlined by many (e.g., Lemos and Morehouse, 2005;Norstrom et al., 2020). Our iterative workshop series to test and improve the FANFAR system (sect. 4.1.2) cannot be attributed to MCDA. Practical MCDA projects often consist of three stakeholder interactions: a first workshop for problem structuring, a second for preference elicitation, and a third for discussing results and revising options, i.e., system configurations (Figure 1). Discontinuous participation can be a challenge (Lang et al., 2012), also for FANFAR. The 3.5-year project involved representatives of at least two institutions from 17 African countries, regional stakeholders, and European partners, reflected in changing numbers and composition of participants (sect. 2.2.3). As Lang et al. (2012), we also encountered the opposite: increasing requests over time and the challenge of keeping participant numbers manageable. We integrated new participants, e.g., by presenting the FANFAR system and MCDA objectives at each workshop. For MCDA, discontinuous participation was unproblematic, as new participants in the second workshop accepted the objectives (Figure 2) and system configurations (Table 2). This indicates that our participant sample was sufficiently large and diverse to cover the main aspects. Another challenge can be vague results when using methods such as sustainability visions, which may conceal potential conflicts (Lang et al., 2012). MCDA has the strength of providing clear results, even for uncertain data (sect. 4.1.2). 
The pluralistic principle aims at creating social learning across multiple axes (step 2e, Table 1), and to build trust, e.g., by recognizing values of people, providing trainings, and capacity building. Sustained interaction with stakeholders, jointly searching for solutions, joint practices, and joint learning foster trust, mutual understanding, and shared perspectives (e.g., Lemos and Morehouse, 2005; Norstrom et al., 2020;Schneider et al., 2019), and "relationships of trust among participants make policymaking and implementation more likely to succeed" (Lemos and Morehouse, 2005; p. 61). Recognizing different expertise, perspectives, values, and interests (e.g., Norstrom et al., 2020;Wuelser et al., 2021) does not require consensus to be reached across conflicting interests, but implies collaboratively engaging with conflicts (Caniglia et al., 2021) to rationalize contested situations (Schneider et al., 2019). A strength of MCDA is that opposing stakeholder interests are part of the methodology, hereby often avoiding conflict about the choice of solutions (Arvai et al., 2001;Gregory et al., 2012a;Gregory et al., 2012b;Marttunen and Hamalainen, 2008). In the weight elicitation sessions, we encouraged stakeholders to discuss diverging preferences about the importance of objectives (sect. 2.2.8), and we recommend allowing for such uncertainty. It helps participants construct their own preferences (Lichtenstein and Slovic, 2006), enables learning and understanding alternative perspectives, and can inform sensitivity analyses (sect. 3.7). In FANFAR, conflicting preferences did not change the ranking of system configurations, and we identified consensus systems (sect. 4.1.2). In other cases, sensitivity analyses based on diverging preferences can help construct better configurations. As interesting observation, in the first FANFAR workshop, participants voted on objectives to include in the MCDA, which did not match an African perspective for all. Some participants criticized the democratic approach, remarking e.g., that "the chief should decide". "Assessing the [interactive] principle should also focus on capturing learning, how the perceptions of actors change throughout the process, and the degree to which a shared perspective emerges" (Norstrom et al., 2020; p. 188). Such research is rarely done in MCDA, but was attempted in FANFAR and a Swiss project. We shortly elicited the importance of objectives at every workshop, hypothesizing that increased shared understanding is mirrored by converging stakeholder preferences (Kuller et al., in prep.). Results were ambiguous, but we found shared agreement of FANFAR stakeholders about the most important objectives. More research to better understand individual cognitive and group decision making processes is needed (Kuller et al., in prep.).

Training and capacity building are components of the pluralistic principle (step 2e, Table 1). To foster joint understanding, commitment, and trust, many of 31 analyzed transdisciplinary projects provided e.g., trainings, or attractive visualizations of recent research (Schneider et al., 2019). Capacity building can be promoted by working in integrated ways of knowledge coproduction discussed above (Caniglia et al., 2021), or with capacity building courses (Wuelser et al., 2021). The FANFAR project offered many training and capacity building opportunities, which cannot be attributed to MCDA.

\subsubsection{Evaluating the co-dissemination and evaluation step "integrating and disseminating knowledge"}

Two-dimensional integration (step 3a, Table 1) implies that project outcomes are reviewed, discussed, and revised from a 785 scientific and societal perspective (Mauser et al., 2013;Lang et al., 2012). Discussing transformation knowledge includes measures, tools, or governance mechanisms to create change in the desirable direction (Schneider et al., 2019). It can include 
prescriptive knowledge, recommending suitable options for realizing intentions (Caniglia et al., 2021). This is a strength of MCDA: in our case, we provided detailed information about good, robust FANFAR system configurations (sect. 4.1). Moreover, MCDA results are discussed with stakeholders and if needed, new consensus options are constructed (Figure 1). We were not able to carry out the fourth FANFAR workshop in West Africa due to the COVID-19 pandemic. We collected some feedback about how well the current FANFAR system meets the 10 objectives in an online survey. The stakeholders were quite satisfied with its performance during the 2020 rainy season (Figure 7), and are willing to use it in future. Although this does not meet requirements of extensive discussions, it was the best available approach. Understanding governance mechanisms is out of the scope of MCDA; in our case, ways to facilitate uptake of the FANFAR system across entire West Africa.

Target products (step 3b, Table 1) should address the original problem, be understandable, and accessible to users (Lemos and Morehouse, 2005;Schneider et al., 2019; Lang et al., 2012). Products include technical publications in appropriate language, data visualizations, and open access online databases (Schneider et al., 2019). In FANFAR, these products cannot be attributed to MCDA. Main product is the operational FANFAR flood forecast and alert system (including operational data collection, assimilation, hydrological modelling, interpretation, and distribution through web visualization and API), where MCDA only helped in the design. Additional products include a multilingual open access knowledge base (https://fanfar.eu/support/), the open source code (https://github.com/hydrology-tep/fanfar-forecast), and video tutorials (www.youtube.com, search: HYPEweb FANFAR). Assuring consistent access, maintenance, updates, and improvements after project termination is a challenge (Lemos and Morehouse, 2005). AGRHYMET has the authority to drive uptake of FANFAR in West Africa and already uses it beyond project activities, e.g., at PRESASS and PRESAGG forums (WMO, 2021) to support the ECOWAS flood management strategy, and in their MSc curriculum. Nevertheless, long term operationalization after EU financing is not guaranteed.

Products should contribute to scientific progress (Jahn et al., 2012), a major challenge being inadequate generalization of case study solutions (Lang et al., 2012). Products are often not reported in scholarly literature (Wuelser et al., 2021), the knowledge thus not advancing scientific progress, and not being adopted in societal praxis of similar projects. We aim to overcome this with this paper and other outputs (FANFAR, 2021). For MCDA, we document the process, and provide details in the Supplementary Information. We encourage hydrologists to use this material. We stress that it is not necessary to conduct a full MCDA in every case. Problem structuring (sect. 4.3.1) can create useful insights (sect. 4.2), and may be easier to apply. The last step 3c (Table 1) is to evaluate societal and scientific impact. MCDA did not contribute to this, although project evaluation would be possible with MCDA. Short-term impacts can be visible in increased citations or attention of nonacademic actors, including download rates or media coverage (Norstrom et al., 2020;Schneider et al., 2019). This occurred; as example, the third FANFAR workshop in Nigeria featured on the national TV news. Building social capacities and establishing stakeholder networks or communities of practice can be very helpful (Lemos and Morehouse, 2005; Schneider et al., 2019). A FANFAR social media group among the West African stakeholders monitored the severe 2020 floods across the region, which in many places were successfully forecasted by the FANFAR system. Indicators of mid-term impacts relate to the uptake of concrete products and to societal effects of the transdisciplinary process such as strategy implementation, or 
amended legislation (Jahn et al., 2012;Norstrom et al., 2020). Long-term impacts are very difficult to measure as they are typically realized far beyond project termination (Norstrom et al., 2020; Schneider et al., 2019). Moreover, due to the complexity of the problems addressed in transdisciplinary projects, it is difficult to establish causal relationships (Lang et al., 2012). Whether the FANFAR flood forecast and alert system will be taken up broadly by West African stakeholders is uncertain. However, it already had societal impact. As one example, the Nigeria Hydrological Services Agency, NIHSA reported that an early warning received from the FANFAR system in September 2020 saved approximately 2500 lives. The warning helped evacuating five communities before the flood destroyed more than 200 houses.

\section{Conclusions}

The MCDA process enabled identifying three good FANFAR system configuration (Research Question RCA; sect. 4.1), which is important to West African stakeholders and those potentially affected by floods. These consensus configurations performed well for all stakeholders, despite their diverging priorities. All stakeholder groups preferred a system producing accurate, clear, and accessible flood risk information that reaches recipients well before floods. To achieve this, most groups would trade-off higher operation and maintenance costs, development time, and several languages. The West African stakeholders preferred a system that works reliably and accurately under difficult conditions in the region, but not necessarily including many advanced features. MCDA demonstrated the robustness of these three configurations given different stakeholder perspectives, model uncertainty, and uncertain expert predictions from different disciplines concerning FANFAR system performance (sect. 4.1.2). The three FANFAR system configurations achieved $63-70 \%$ of the entire set of objectives for all stakeholder groups. Interestingly, the uncertainty analysis allowed to better distinguish between system configurations than standard MCDA without uncertainty. We recommend using a participatory MCDA process to find suitable options in hydrology research. Emphasizing objectives follows Value Focused Thinking (VFT), which helped avoiding potential conflicts about system configuration. Important for practice, VFT was also beneficial to guide early technical FANFAR system development, before MCDA results were available. However, eliciting the trade-offs that stakeholders were willing to make was necessary for later setting priorities, and the robustness of results could not have been evaluated without the full MCDA (RQB; sect. 4.2).

From the perspective of sustainability science and transdisciplinary research, MCDA meets many, but not all requirements (RCD; Table 4). The proposed evaluation framework based on literature proved very useful for our critical analysis of MCDA

845 (Table 1). We invite others to apply and evaluate it in their cases. Having practice-oriented hydrology research in mind, we included elements underrepresented in literature, but crucial to earth systems sciences: uncertainty and integrating interdisciplinary knowledge. We evaluated MCDA as a transdisciplinary process along the three framework steps (sect. 4.3). MCDA can only partially contribute to co-design (step 1; Table 4; sect. 4.3.1), and is not appropriate for building the research team or alliances with regional partners. However, if MCDA is understood as a process that includes problem structuring, it can support joint problem framing. Stakeholder analysis is one method to identify those that should be involved; we recommend using a 
relatively simple questionnaire. MCDA problem structuring also helps defining objectives shared by researchers and practitioners, and we recommend creativity techniques for engaging participants in developing options (i.e., system configurations). Joint MCDA problem structuring allowed bringing a relatively large number of stakeholders on board. The strength of a participatory MCDA process lies in its contribution to knowledge co-production (step 2; sect. 4.3.2). MCDA provides an integrative, consistent framework to produce transferable knowledge across different disciplines, using marginal value functions (sect. 2.2.8). Interdisciplinary integration was rarely emphasized in the reviewed literature, and could be a contribution of future research in the earth systems sciences. The same goes for explicit consideration of various types of uncertainty, which is a strength of MCDA (sect. 4.1.2). MCDA can also provide clear results and identify consensus system configurations by integrating conflicting stakeholder interests into the model (sect. 3.5). An MCDA process can enable social learning of participants, but does not foster training and capacity building. Finally, MCDA includes discussing results with stakeholders and constructing improved consensus configurations, but this focus is narrow (step 3, sect. 4.3.3). MCDA does not achieve important elements such as analyzing governance mechanisms, and developing or implementing actions and products. In FANFAR, we thus carried out complementary activities to be more comprehensive, beyond the limits of MCDA. We received feedback that stakeholders are willing to use the FANFAR system (Figure 7), and indications that it is already effective.

865 As many others, we believe that transdisciplinary research contributes to solving the complex problems our world is facing, and to advancing scientific progress. We hope that this paper documents and helps to better understand such a process in a complex setting: producing a good flood forecast and alert system for West Africa, together with many stakeholders. We contribute to literature by analyzing the strengths but also limits of a comprehensive MCDA process for such endeavors. We encourage our colleagues from the earth system sciences to engage in transdisciplinary research with stakeholders and society.

\section{Data availability}

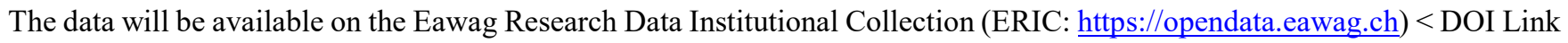
to be provided once paper is accepted $>$

7 Supplement link ( $<$ will be included by Copernicus, if applicable $>$ )

In the Supplementary Information (SI), we provide ample material to guide readers unfamiliar with Multi-Criteria Decision 875 Analysis (MCDA) through all steps. This includes a Methods section (generating system configurations, eliciting weights, MCDA model, sensitivity analyses, stakeholder feedback), and a Results section (stakeholder analysis, objectives and attributes, system configurations, predictions, marginal value functions, weights, MCDA results, and stakeholder feedback). 


\section{Author contribution}

Judit Lienert: Conceptualization, funding acquisition, investigation, methodology, project administration, resources, supervision, validation, writing - original draft preparation. Jafet Andersson: Funding acquisition, investigation, project administration, writing - review \& editing. Daniel Hofmann: Data curation, formal analysis, visualization, validation, writing - original draft preparation. Francisco Silva Pinto: Formal analysis, investigation, methodology, project administration, writing - review $\&$ editing. Martijn Kuller: Investigation, project administration, supervision, writing - review \& editing.

\section{Competing interests}

885 The authors declare that they have no conflict of interest.

\section{Special issue statement}

This paper was prepared for the special issue: "Contributions of transdisciplinary approaches to hydrology and water resources management"; < The statement on a corresponding special issue will be included by Copernicus, if applicable >

\section{Acknowledgements}

890 This project received funding from the European Union's Horizon 2020 research and innovation programme under grant agreement No. 780118: FANFAR (Reinforced cooperation to provide operational flood forecasting and alerts in West Affica (FANFAR, 2021). We thank Eawag, the Swiss Federal Institute of Aquatic Science and Technology, for providing additional funding to support the project during the COVID-19 prolongation period. We sincerely thank Abdou Ali, Addi Shuaib Olorunoje, Aishat Ibrahim, Alice Aubert, Aytor Naranjo, Berit Arheimer, Bernard Minoungou, Bode Gbobaniyi, Cletus Musa, David Gustafsson, Emilie Breviere, Emmanuel Mathot, Fabrizio Pacini, Fridolin Haag, Kevin Schönholzer, Léonard Santos, Lorna Little, Melissande Machefer, Mohamed Hamatan, Philipp Beutler, Sara Schmid, Tharcisse Ndayizigiye, and Umar Magashi for their invaluable support when preparing the workshops, collecting data, and data analysis. We are truly grateful for the inspiring collaboration with the workshop participants, and we wish to sincerely thank them for their kindness and enthusiasm to work with us. We also thank three anonymous reviewers and the editors of this Special Issue for their helpful feedback.

\section{References}

Abdullah, M. F., Siraj, S., and Hodgett, R. E.: An Overview of Multi-Criteria Decision Analysis (MCDA) Application in Managing Water-Related Disaster Events: Analyzing 20 Years of Literature for Flood and Drought Events, Water, 13, 10.3390/w13101358, 2021. 
Aich, V., Liersch, S., Vetter, T., Fournet, S., Andersson, J. C. M., Calmanti, S., van Weert, F. H. A., Hattermann, F. F., and

Paton, E. N.: Flood projections within the Niger River Basin under
Environment, 562, 666-677, 10.1016/j.scitotenv.2016.04.021, 2016.

Andersson, J., Ali, A., Arheimer, B., Crochemore, L., Gbobaniyi, B., Gustafsson, D., Hamatan, M., Kuller, M., Lienert, J., Machefer, M., Magashi, U., Mathot, E., Minoungou, B., Naranjo, A., Ndayizigiye, T., Pacini, F., Silva Pinto, F., Santos, L., and Shuaib, A.: Flood forecasting and alerts in West Africa - experiences from co-developing a pre-operational system at regional scale, EGU General Assembly 2020, 4-8 May 2020, Online, https://doi.org/10.5194/egusphere-egu2020-7660, 2020a. Andersson, J., Santos, L., Isberg, K., Gustafsson, D., Musuuza, J., Minoungou, B., and Crochemore, L.: Deliverable: D3.2. Report documenting and explaining the hydrological models, European Union, Horizon 2020, Innovation Action ICT programme, Project: 780118 FANFAR; DOI: 10.13140/RG.2.2.17369.85601 pp. 41, 2020b.

Andersson, J. C. M., Arheimer, B., Traoré, F., Gustafsson, D., and Ali, A.: Process refinements improve a hydrological model

915 concept applied to the Niger River basin, Hydrological Processes, 31, 4540-4554, https://doi.org/10.1002/hyp.11376, 2017.

Arheimer, B., Lindstrom, G., and Olsson, J.: A systematic review of sensitivities in the Swedish flood-forecasting system, Atmos. Res., 100, 275-284, 10.1016/j.atmosres.2010.09.013, 2011.

Arheimer, B., Pimentel, R., Isberg, K., Crochemore, L., Andersson, J. C. M., Hasan, A., and Pineda, L.: Global catchment modelling using World-Wide HYPE (WWH), open data, and stepwise parameter estimation, Hydrol. Earth Syst. Sci., 24, 535559, 10.5194/hess-24-535-2020, 2020.

Arvai, J. L., Gregory, R., and McDaniels, T. L.: Testing a structured decision approach: Value-focused thinking for deliberative risk communication, Risk Analysis, 21, 1065-1076, 2001.

Basher, R.: Global early warning systems for natural hazards: systematic and people-centred, Philosophical Transactions of the Royal Society a-Mathematical Physical and Engineering Sciences, 364, 2167-2180, 10.1098/rsta.2006.1819, 2006.

925 Belton, V., and Stewart, T. S.: Multiple Criteria Decision Analysis: An Integrated Approach, Springer Science+Business Media Springer, Dordrecht, The Netherlands, 2002.

Berg, P., Almén, F., and Bozhinova, D.: HydroGFD3.0: a 25 km global near real-time updated precipitation and temperature data set, Earth Syst. Sci. Data Discuss., 2020, 1-18, 10.5194/essd-2020-236, 2020.

Bierens, S., Boersma, K., and van den Homberg, M. J. C.: The legitimacy, accountability, and ownership of an impact-based

930 forecasting model in disaster governance, Politics Gov., 8, 445-455, 10.17645/pag.v8i4.3161, 2020.

Bond, S. D., Carlson, K. A., and Keeney, R. L.: Generating objectives: Can decision makers articulate what they want?, Manage. Sci., 54, 56-70, https://doi.org/10.1287/mnsc.1070.0754, 2008.

Caniglia, G., Luederitz, C., von Wirth, T., Fazey, I., Martin-Lopez, B., Hondrila, K., Konig, A., von Wehrden, H., Schapke, N. A., Laubichler, M. D., and Lang, D. J.: A pluralistic and integrated approach to action-oriented knowledge for sustainability,

935 Nat. Sustain., 4, 93-100, 10.1038/s41893-020-00616-z, 2021.

Carr, G., Gomes, S. L., Hermans, L., Krueger, T., Lindquist, E., Thaler, T., and Slater, L.: Special issue: Contributions of transdisciplinary approaches to hydrology and water resources management Hydrol. Earth Syst. Sci., https://hess.copernicus.org/articles/special issue1092.html, 2021.

Shiny: Web Application Framework for R R package version 1.5: https://cran.r-project.org/web/packages/shiny/index.html, 2020.

Convertino, M., Annis, A., and Nardi, F.: Information-theoretic portfolio decision model for optimal flood management, Environmental Modelling \& Software, 119, 258-274, 10.1016/j.envsoft.2019.06.013, 2019.

de Brito, M. M., and Evers, M.: Multi-criteria decision-making for flood risk management: a survey of the current state of the art, Natural Hazards and Earth System Sciences, 16, 1019-1033, 10.5194/nhess-16-1019-2016, 2016.

945 de Brito, M. M., Evers, M., and Almoradie, A. D. S.: Participatory flood vulnerability assessment: a multi-criteria approach, Hydrol. Earth Syst. Sci., 22, 373-390, 10.5194/hess-22-373-2018, 2018.

Donetto, S., Pierri, P., Tsianakas, V., and Robert, G.: Experience-based Co-design and Healthcare Improvement: Realizing Participatory Design in the Public Sector, Des. J., 18, 227-248, 10.2752/175630615x14212498964312, 2015.

Eisenführ, F., Weber, M., and Langer, T.: Rational Decision Making, Springer, Berlin, Heidelberg, New York, 2010.

950 Emerton, R. E., Stephens, E. M., Pappenberger, F., Pagano, T. C., Weerts, A. H., Wood, A. W., Salamon, P., Brown, J. D., Hjerdt, N., Donnelly, C., Baugh, C. A., and Cloke, H. L.: Continental and global scale flood forecasting systems, Wiley Interdiscip. Rev.-Water, 3, 391-418, 10.1002/wat2.1137, 2016. 
Evers, M., Almoradie, A., and de Brito, M. M.: Enhancing Flood Resilience Through Collaborative Modelling and Multicriteria Decision Analysis (MCDA), in: Urban Disaster Resilience and Security: Addressing Risks in Societies, edited by: Fekete, A., and Fiedrich, F., Urban Book Series, 221-236, 2018.

FANFAR: Operational flood forecasting and alerts in West Africa. A transdisciplinary international project funded by the European Union.: https://fanfar.eu and https://cordis.europa.eu/project/id/780118/results, access: 30.09.2021, 2021.

Figueira, J., and Roy, B.: Determining the weights of criteria in the ELECTRE type methods with a revised Simos' procedure, European Journal of Operational Research, 139, 317-326, https://doi.org/10.1016/S0377-2217(01)00370-8, 2002.

960 Gregory, R., Failing, L., Harstone, M., Long, G., McDaniels, T., and Ohlson, D.: Structured decision making: A practical guide to environmental management choices, Wiley-Blackwell Publishing, 2012a.

Gregory, R., Long, G., Colligan, M., Geiger, J. G., and Laser, M.: When experts disagree (and better science won't help much): Using structured deliberations to support endangered species recovery planning, Journal of Environmental Management, 105, 30-43, 10.1016/j.jenvman.2012.03.001, 2012b.

965 Grimble, R., and Wellard, K.: Stakeholder methodologies in natural resource management: A review of principles, contexts, experiences and opportunities, Agricultural Systems, 55, 173-193, 10.1016/S0308-521X(97)00006-1, 1997.

Haag, F., Lienert, J., Schuwirth, N., and Reichert, P.: Identifying non-additive multi-attribute value functions based on uncertain indifference statements, Omega-International Journal of Management Science, 85, 49-67, 10.1016/j.omega.2018.05.011,2019a.

970 Haag, F., Reichert, P., Maurer, M., and Lienert, J.: Integrating uncertainty of preferences and predictions in decision models: An application to regional wastewater planning, Journal of environmental management, 252, 109652-109652, 10.1016/j.jenvman.2019.109652, 2019b.

Haag, F., Zuercher, S., and Lienert, J.: Enhancing the elicitation of diverse decision objectives for public planning, European Journal of Operational Research, 279, 912-928, 10.1016/j.ejor.2019.06.002, 2019c.

975 Haag, F., Aubert, A. H., and Lienert, J.: Supporting environmental decisions with multiple objectives, multiple stakeholders, and uncertainty with the ValueDecisions web app, Under review, subm.

Howard, R. A.: Decision-analysis - Practice and promise, Manage. Sci., 34, 679-695, 10.1287/mnsc.34.6.679, 1988.

Jahn, T., Bergmann, M., and Keil, F.: Transdisciplinarity: Between mainstreaming and marginalization, Ecological Economics, 79, 1-10, 10.1016/j.ecolecon.2012.04.017, 2012.

980 Janis, I. L.: Victims of Groupthink, Houghton Mifflin, New York, 1972.

Keeney, R. L.: Decision-Analysis - an Overview, Oper. Res., 30, 803-838, https://doi.org/10.1287/opre.30.5.803, 1982.

Keeney, R. L.: Value-focused thinking: Identifying decision opportunities and creating alternatives, European Journal of Operational Research, 92, 537-549, https://doi.org/10.1016/0377-2217(96)00004-5, 1996.

Kendall, M. G.: A new measure of rank correlation, Biometrika, 30, 81-93, 10.2307/2332226, 1938.

985 Kuller, M., Silva Pinto, F., Schönholzer, K., and Lienert, J.: Effective risk communication for early flood warning in WestAfrica, EGU General Assembly 2020, Due to coronavirus pandemic, EGU2020 has gone virtual with Sharing Geoscience Online; https://doi.org/10.5194/egusphere-egu2020-9425, 4.-8.05.2020, 2020.

Kuller, M., Schönholzer, K., and Lienert, J.: Creating effective flood warnings: a framework from a critical review, J. Hydrol., 602, 126708, https://doi.org/10.1016/j.jhydrol.2021.126708, 2021.

990 Kuller, M., Beutler, P., and Lienert, J.: The role and implications of preference change in stakeholder group-decision processes in the public sector (working title), in prep.

Lang, D. J., Wiek, A., Bergmann, M., Stauffacher, M., Martens, P., Moll, P., Swilling, M., and Thomas, C., J.: Transdisciplinary research in sustainability science: practice, principles, and challenges, Sustainability Science, 7, 25-43, https://link.springer.com/article/10.1007/s11625-011-0149-x, 2012.

995 Lemos, M. C., and Morehouse, B. J.: The co-production of science and policy in integrated climate assessments, Glob. Environ. Change-Human Policy Dimens., 15, 57-68, 10.1016/j.gloenvcha.2004.09.004, 2005.

Lienert, J., Schnetzer, F., and Ingold, K.: Stakeholder analysis combined with social network analysis provides fine-grained insights into water infrastructure planning processes, Journal of Environmental Management, 125, 134-148, 10.1016/j.jenvman.2013.03.052, 2013.

1000 Lienert, J., Scholten, L., Egger, C., and Maurer, M.: Structured decision-making for sustainable water infrastructure planning and four future scenarios, EURO Journal on Decision Processes, 3, 107-140, http://dx.doi.org/10.1007/s40070-014-0030-0, 2015. 
Lienert, J., Andersson, J., Hofmann, D., Silva Pinto, F., and Kuller, M.: Deliverable D2.2. Report on the co-design workshops in FANFAR to create a flood forecast and alert system for West Africa European Union, Horizon 2020, Innovation Action

URL: https://www.dora.lib4ri.ch/eawag/islandora/object/eawag:21545, Deliverable D2.2, 29, 2020.

Liu, S., Maclean, K., and Robinson, C.: A cost-effective framework to prioritise stakeholder participation options, Euro Journal on Decision Processes, 7, 221-241, 10.1007/s40070-019-00103-7, 2019.

Marttunen, M., and Hamalainen, R. P.: The decision analysis interview approach in the collaborative management of a large regulated water course, Environmental Management, 42, 1026-1042, 10.1007/s00267-008-9200-9, 2008.

Marttunen, M., Lienert, J., and Belton, V.: Structuring problems for Multi-Criteria Decision Analysis in practice: A literature review of method combinations, European Journal of Operational Research, 263, 1-17, 10.1016/j.ejor.2017.04.041, 2017.

Marttunen, M., Belton, V., and Lienert, J.: Are objectives hierarchy related biases observed in practice? A meta-analysis of environmental and energy applications of Multi-Criteria Decision Analysis, European Journal of Operational Research, 265,

1015 178-194, 10.1016/j.ejor.2017.02.038, 2018.

Marttunen, M., Haag, F., Belton, V., Mustajoki, J., and Lienert, J.: Methods to inform the development of concise objectives hierarchies in multi-criteria decision analysis, European Journal of Operational Research, 277, 604-620, 10.1016/j.ejor.2019.02.039, 2019.

Massazza, G., Tarchiani, V., Andersson, J. C. M., Ali, A., Ibrahim, M. H., Pezzoli, A., De Filippis, T., Rocchi, L., Minoungou,

1020 B., Gustafsson, D., and Rosso, M.: Downscaling Regional Hydrological Forecast for Operational Use in Local Early Warning: HYPE Models in the Sirba River, Water, 12, 3504, https://doi.org/10.3390/w12123504 2020.

Mauser, W., Klepper, G., Rice, M., Schmalzbauer, B. S., Hackmann, H., Leemans, R., and Moore, H.: Transdisciplinary global change research: the co-creation of knowledge for sustainability, Current Opinion in Environmental Sustainability, 5, 420431, 10.1016/j.cosust.2013.07.001, 2013.

1025 Montibeller, G., and von Winterfeldt, D.: Cognitive and motivational biases in decision and risk analysis, Risk Analysis, 35, 1230-1251, 10.1111/risa.12360, 2015.

Nachappa, T. G., Piralilou, S. T., Gholamnia, K., Ghorbanzadeh, O., Rahmati, O., and Blaschke, T.: Flood susceptibility mapping with machine learning, multi-criteria decision analysis and ensemble using Dempster Shafer Theory, J. Hydrol., 590, 10.1016/j.jhydrol.2020.125275, 2020.

1030 NBA (Niger Basin Authority): SATH-NBA (Satellite based water monitoring and flow forecasting for the Niger River Basin: http://www.sath.abn.ne/, access: 09.11.2020, 2020.

Nka, B. N., Oudin, L., Karambiri, H., Paturel, J. E., and Ribstein, P.: Trends in floods in West Africa: analysis based on 11 catchments in the region, Hydrol. Earth Syst. Sci., 19, 4707-4719, 10.5194/hess-19-4707-2015, 2015.

Norstrom, A. V., Cvitanovic, C., Lof, M. F., West, S., Wyborn, C., Balvanera, P., Bednarek, A. T., Bennett, E. M., Biggs, R.,

1035 de Bremond, A., Campbell, B. M., Canadell, J. G., Carpenter, S. R., Folke, C., Fulton, E. A., Gaffney, O., Gelcich, S., Jouffray, J. B., Leach, M., Le Tissier, M., Martin-Lopez, B., Louder, E., Loutre, M. F., Meadow, A. M., Nagendra, H., Payne, D., Peterson, G. D., Reyers, B., Scholes, R., Speranza, C. I., Spierenburg, M., Stafford-Smith, M., Tengo, M., van der Hel, S., van Putten, I., and Osterblom, H.: Principles for knowledge co-production in sustainability research, Nat. Sustain., 3, 182-190, 10.1038/s41893-019-0448-2, 2020.

1040 O'Hagan, A.: Expert Knowledge Elicitation: Subjective but Scientific, American Statistician, 73, 69-81, 10.1080/00031305.2018.1518265, 2019.

OCHA: West and Central Africa: flooding situation, UN Office for the Coordination of Humanitarian Affairs (OCHA); https://www.unocha.org/, 2, 2020.

Pang, B., Yue, J. J., Huang, Z. Q., and Zhang, R.: Parameter uncertainty assessment of a flood forecasting model using multiple

1045 objectives, Journal of Flood Risk Management, 12, 10.1111/jfr3.12493, 2019.

Passerotti, G., Massazza, G., Pezzoli, A., Bigi, V., Zsótér, E., and Rosso, M.: Hydrological Model Application in the Sirba River: Early Warning System and GloFAS Improvements, Water, 12, 620, 10.3390/w12030620, 2020.

Paulus, P. B., and Yang, H. C.: Idea generation in groups: A basis for creativity in organizations, Organizational Behavior and Human Decision Processes, 82, 76-87, 10.1006/obhd.2000.2888, 2000.

1050 Perera, D., Seidou, O., Agnihotri, J., Rasmy, M., Smakhtin, V., Coulibaly, P., and Mehmood, H.: Flood early warning systems: a review of benefits, challenges and prospects, United Nations University Institute for Water, Environment and Health (UNUINWEH); https://inweh.unu.edu/, Hamilton, Canada, 26, 2019. 
Pham, B. T., Luu, C., Phong, T. V., Nguyen, H. D., Le, H. V., Tran, T. Q., Ta, H. T., and Prakash, I.: Flood risk assessment using hybrid artificial intelligence models integrated with multi-criteria decision analysis in Quang Nam Province, Vietnam, J. Hydrol., 592, 10.1016/j.jhydrol.2020.125815, 2021.

Pictet, J., and Bollinger, D.: Extended use of the cards procedure as a simple elicitation technique for MAVT. Application to public procurement in Switzerland, European Journal of Operational Research, 185, 1300-1307, 10.1016/j.ejor.2006.05.051, 2008.

R Core Team: R: A language and environment for statistical computing, Version 3.3.1, R Foundation for Statistical Computing, 1060 http://www.R-project.org/, Vienna, Austria, 2018.

Reed, M. S., Graves, A., Dandy, N., Posthumus, H., Hubacek, K., Morris, J., Prell, C., Quinn, C. H., and Stringer, L. C.: Who's in and why? A typology of stakeholder analysis methods for natural resource management, Journal of Environmental Management, 90, 1933-1949, 10.1016/j.jenvman.2009.01.001, 2009.

Reichert, P., Schuwirth, N., and Langhans, S. D.: Constructing, evaluating and visualizing value and utility functions for decision support, Environmental Modelling \& Software, 46, 283-291, https://doi.org/10.1016/j.envsoft.2013.01.017, 2013.

Reichert, P., Langhans, S. D., Lienert, J., and Schuwirth, N.: The conceptual foundation of environmental decision support, Journal of Environmental Management, 154, 316-332, 10.1016/j.jenvman.2015.01.053, 2015.

Reichert, P., Niederberger, K., Rey, P., Helg, U., and Haertel-Borer, S.: The need for unconventional value aggregation techniques: experiences from eliciting stakeholder preferences in environmental management, EURO Journal on Decision Processes, 7, 197-219, 10.1007/s40070-019-00101-9, 2019.

Ronco, P., Bullo, M., Torresan, S., Critto, A., Olschewski, R., Zappa, M., and Marcomini, A.: KULTURisk regional risk assessment methodology for water-related natural hazards - Part 2: Application to the Zurich case study, Hydrol. Earth Syst. Sci., 19, 1561-1576, 10.5194/hess-19-1561-2015, 2015.

Rosenhead, J., and Mingers, J.: Rational Analysis for a Problematic World Revisited: Problem Structuring Methods for 1075 Complexity, Uncertainty and Conflict, John Wiley \& Sons, Chichester, 2001.

Roudier, P., Ducharne, A., and Feyen, L.: Climate change impacts on runoff in West Africa: a review, Hydrol. Earth Syst. Sci., 18, 2789-2801, 10.5194/hess-18-2789-2014, 2014.

Samanta, S., Koloa, C., Pal, D. K., and Palsamanta, B.: Flood Risk Analysis in Lower Part of Markham River Based on MultiCriteria Decision Approach (MCDA), Hydrology, 3, 10.3390/hydrology3030029, 2016.

1080 Schneider, F., Giger, M., Harari, N., Moser, S., Oberlack, C., Providoli, I., Schmid, L., Tribaldos, T., and Zimmermann, A.: Transdisciplinary co-production of knowledge and sustainability transformations: Three generic mechanisms of impact generation, Environmental Science \& Policy, 102, 26-35, 10.1016/j.envsci.2019.08.017, 2019.

Schuol, J., Abbaspour, K. C., Yang, H., Srinivasan, R., and Zehnder, A. J. B.: Modeling blue and green water availability in Africa, Water Resour. Res., 44, 10.1029/2007wr006609, 2008.

1085 Silva Pinto, F., and Lienert, J.: Deliverable: D2.1. Report activities to establish co-design committee, stakeholder analysis, European Union, Horizon 2020, Innovation Action ICT programme; Project: 780118 FANFAR, Deliverable D2.1, 48, 2018. Sultan, B., Lejeune, Q., Menke, I., Maskell, G., Lee, K., Noblet, M., Sy, I., and Roudier, P.: Current needs for climate services in West Africa: Results from two stakeholder surveys, Clim. Serv., 18, 10.1016/j.cliser.2020.100166, 2020.

Tang, Z. Q., Zhang, H., Yi, S. Z., and Xiao, Y. F.: Assessment of flood susceptible areas using spatially explicit, probabilistic multi-criteria decision analysis, J. Hydrol., 558, 144-158, 10.1016/j.jhydrol.2018.01.033, 2018.

UNISDR: Early warning practices can save lives: good practices and lessons learned, United Nations Secretariat of the International Strategy for Disaster Reduction (UNISDR); https://www.undrr.org/, Bonn, Germany, 67, 2010.

WMO (World Meteorological Organization): Regional Climate Outlook Forums: https://public.wmo.int/en/ourmandate/climate/regional-climate-outlook-products, access: 25.02.2021, 2021.

1095 Wuelser, G., Adler, C., Breu, T., Hadorn, G. H., Wiesmann, U., and Pohl, C.: On which common ground to build? Transferable knowledge across cases in transdisciplinary sustainability research, Sustainability Science, 15, 10.1007/s11625-021-01010-0, 2021.

Zheng, J., Egger, C., and Lienert, J.: A scenario-based MCDA framework for wastewater infrastructure planning under uncertainty, Journal of Environmental Management, 183, Part 3, 895-908, http://dx.doi.org/10.1016/j.jenvman.2016.09.027, 2016. 